\title{
Development of a Microphone Phased Array Capability for the Langley 14- by 22-Foot Subsonic Tunnel
}

\author{
William M. Humphreys, Jr., Thomas F. Brooks ${ }^{\dagger}$, Christopher J. Bahr ${ }^{\ddagger}$, \\ Taylor B. Spalt ${ }^{\S}$, Scott M. Bartram ", William G. Culliton \\ NASA Langley Research Center, Hampton, Virginia 23681-2199 \\ Lawrence E. Becker ${ }^{¥}$ \\ Northrop Grumman Corporation, Hampton, Virginia 23681-2199
}

\begin{abstract}
A new aeroacoustic measurement capability has been developed for use in open-jet testing in the NASA Langley 14- by 22-Foot Subsonic Tunnel (14x22 tunnel). A suite of instruments has been developed to characterize noise source strengths, locations, and directivity for both semi-span and full-span test articles in the facility. The primary instrument of the suite is a fully traversable microphone phased array for identification of noise source locations and strengths on models. The array can be mounted in the ceiling or on either side of the facility test section to accommodate various test article configurations. Complementing the phased array is an ensemble of streamwise traversing microphones that can be placed around the test section at defined locations to conduct noise source directivity studies along both flyover and sideline axes. A customized data acquisition system has been developed for the instrumentation suite that allows for command and control of all aspects of the array and microphone hardware, and is coupled with a comprehensive data reduction system to generate information in near real time. This information includes such items as time histories and spectral data for individual microphones and groups of microphones, contour presentations of noise source locations and strengths, and hemispherical directivity data. The data acquisition system integrates with the $14 \times 22$ tunnel data system to allow real time capture of facility parameters during acquisition of microphone data. Performance analysis of the array using a coarray figure of merit and synthetic point spread functions using monopole sources show that the array design is adequate for its intended purpose in the facility. Although the instrumentation suite is designed to characterize noise for a variety of test articles in the $14 \times 22$ tunnel, this paper concentrates on use of the instruments for two specific campaigns in the facility, namely a full-span NASA Hybrid Wing Body (HWB) model entry and a semi-span Gulfstream aircraft model entry, tested in the facility in the winter of 2012 and spring of 2013, respectively.
\end{abstract}

\section{Introduction}

$\mathrm{T}$ he NASA Aeronautics Research Mission Directorate's Integrated Systems Research Program includes in its portfolio the Environmentally Responsible Aviation (ERA) Project. The goal of the ERA Project is to explore vehicle concepts and technologies that improve fuel efficiencies, reduce noise levels, and decrease harmful emissions for both the current and future fleet of aircraft in the national air transportation system. ${ }^{1}$ Two of the three subprojects under ERA, namely Airframe Technology (AT) and

\footnotetext{
${ }^{*}$ Senior Researcher, Advanced Sensing and Optical Measurement Branch, MS 493, Senior Member AIAA

${ }^{\dagger}$ Senior Research Scientist, Aeroacoustics Branch, MS 461, Fellow AIAA

${ }^{\ddagger}$ Research Aerospace Engineer, Aeroacoustics Branch, MS 461, Member AIAA

${ }^{\S}$ Research Student Trainee, Aeroacoustics Branch, MS 461, Student Member AIAA

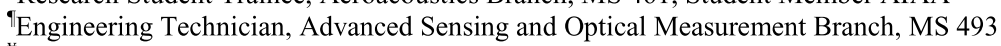

${ }^{\ddagger}$ Senior Engineer, MS 461
}

1 of 24

American Institute of Aeronautics and Astronautics 
Vehicle Systems Integration (VSI), have among their goals the reduction of aircraft noise by 42 cumulative EPNL dB below Stage 4. Methods to achieve this include the reduction of flap and landing gear noise, the identification of noise reduction benefits for propulsion airframe aeroacoustics (PAA) advanced designs, and the testing of non-conventional vehicle concepts that have the potential to meet significant noise reduction metrics. The enabling infrastructure needed to meet these goals include a robust suite of ground test facilities and instrumentation capable of accurately assessing the performance of advanced aircraft designs and noise mitigation concepts.

To meet the needs of the ERA AT and VSI subprojects, a new aeroacoustic measurement capability has been developed for use in open-jet testing in the NASA Langley 14- by 22-foot Subsonic Tunnel (14x22 tunnel). The $14 \times 22$ tunnel has a long history of supporting acoustic measurements, particularly for rotorcraft and engine fan noise models (see Figure 1). The new capability builds on these past successes by providing a suite of instruments developed to fully characterize noise source strengths, locations, and directivity for both semi-span and full-span test articles in the facility. The primary instrument of the suite is a fully traversable microphone phased array for identification of noise source locations and strengths on models. The array can be mounted in the ceiling or on either side of the test section to accommodate various test article configurations. Complementing the phased

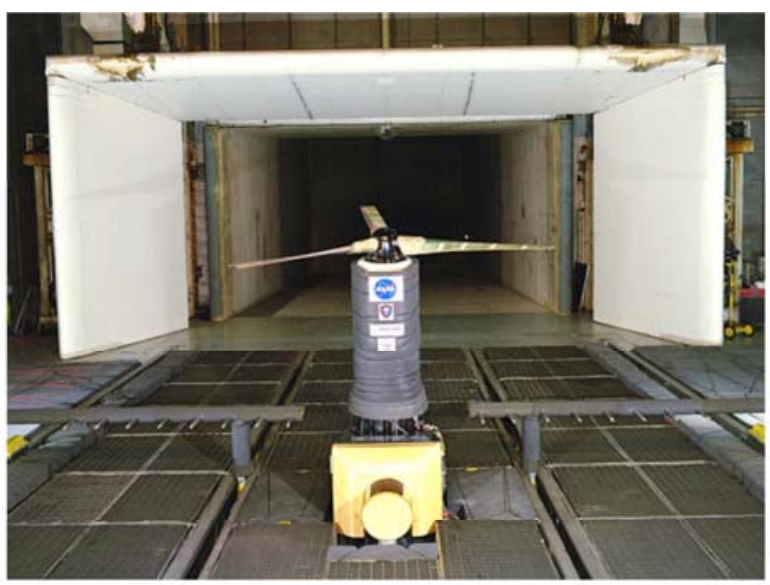

Figure 1. Rotorcraft model, traversable acoustic rake, and treatments in the $14 \times 22$ tunnel during a 1998 entry. array is an ensemble of streamwise traversing microphones that can be placed around the test section at defined locations to conduct noise source directivity studies along both flyover and sideline axes.

This paper summarizes in detail the design of the new instrumentation suite, the construction of the hardware systems, and the results of performance analyses for the phased array. Sample data products generated by the instrumentation are shown. Although the suite is designed to characterize noise for a variety of test articles in the $14 \times 22$ tunnel, this paper will concentrate on descriptions of the instruments for two specific entries in the tunnel. These are a 5.8-percent, full-span NASA Hybrid Wing Body (HWB) model $^{2}$ and an 18-percent, semi-span Gulfstream aircraft model ${ }^{3}$, tested in the winter of 2012 and spring of 2013, respectively.

\section{Test Facility}

The 14- by 22-Foot Subsonic Tunnel is an atmospheric, closed-return tunnel that permits the testing of a variety of fixed and rotary wing aircraft and test articles, both powered and un-powered. The tunnel has a contraction area ratio of 9:1. Using a 12,000 horsepower drive system, the tunnel can generate airflows up to Mach 0.3, corresponding to a maximum Reynolds number of $2.2 \times 10^{6}$ per foot. The test section has dimensions of 14.5 feet high by 21.75 feet wide by 50 feet long and can be configured for either fully enclosed operation or for partial open-jet (floor in place) operation. Removable model carts can be lowered and raised in the floor of the test section to facilitate model changes. For acoustic testing, the floor of the test section can be lowered approximately 3 feet to permit the installation of rigid steel frame baskets containing sound absorbing acoustic foam wedges topped with 2-inch foam sheets. Additionally, foam sheets can be applied to the floors outside of the test section and acoustic foam wedges and perforated plates attached to the raised ceiling and outer sidewalls of the test section (see

2 of 24

American Institute of Aeronautics and Astronautics 
Figure 2). When combined with the floor baskets, the treatment creates an effective semi-anechoic environment in the open-jet test section that minimizes unwanted acoustic reflections.

A major facility upgrade was required to accommodate the installation of the new microphone phased array in the ceiling of the tunnel for use in testing full-span models in open-jet mode. ${ }^{4}$ As part of the upgrade, a two-axis overhead traverse system was fabricated by Jacobs Engineering ${ }^{*}$ and installed above the facility crane rail system in the ceiling of the test section. The overhead traverse has the ability to translate along the full length and width of the test section. The optimal height of the traverse carriage above the floor of the tunnel was determined in the summer of 2010 via detailed microphone rake measurements of the thickness of the upper shear layer in the open jet. The traverse carriage height was adjusted to ensure that buffet of the phased array panel was minimized across the entire speed range of the tunnel. A unique motorized winch system was developed to allow the array to be lowered to the floor of the test section to accommodate installation, removal, and maintenance of the panel containing the microphones. Intersecting serpentine cable trays in the ceiling of the tunnel were

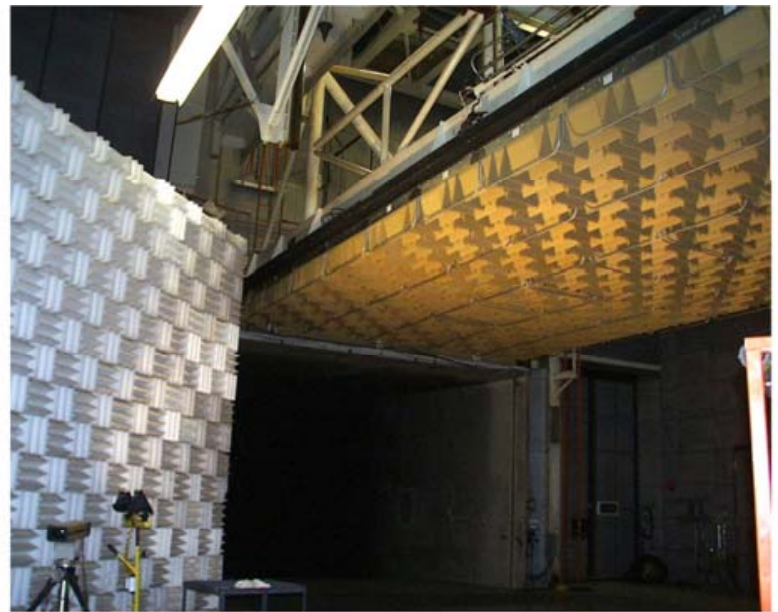

Figure 2. Ceiling and sidewall noise treatments in $14 \times 22$ test section. installed to route signal cables from the overhead traverse carriage into the tunnel control room. Cables conduits were also installed to route signal cables from the far side of the test section to the control room. Finally, the area directly above the tunnel nozzle was modified to provide a storage area for the traverse carriage and array panel when not in use.

In addition to the new overhead traverse, four separate 44-foot linear traversing rails were manufactured by Aerotech, Inc. for use on the floor of the test section. Two primary configurations of these rails have been used in the test section: (1) two rails mounted on each side of the test section supporting open frame towers to which individual directivity microphones can be attached, and (2) two rails mounted on only one side of the test section to which the phased array panel can be attached via an aluminum mounting frame for open-jet testing of semi-span models. Figure 3 illustrates the first configuration for full-span HWB model testing. In this figure the phased array panel can be seen in the ceiling of the test section attached to the overhead traverse carriage. Two towers of directivity microphones (on the left and right sides of the figure) can been seen mounted to pairs of the linear traversing rails. Figure 4 illustrates the second configuration for testing of a semi-span Gulfstream aircraft model. In this configuration the phased array panel is mounted to two of the linear traversing rails and faces the pressure side of the wing. In both figures acoustic treatment can be seen applied to the ceiling, floor, and sides of the test section to create the semi-anechoic environment.

Note that the coordinate system defined for acoustic testing in the $14 \times 22$ tunnel aligns the $\mathrm{x}$-axis with the tunnel streamwise flow direction, the y-axis toward the "south" wall of the test section (away from the control room side), and the z-axis vertically. Unless otherwise noted, this is the coordinate system used for all subsequent discussions of measurements in the facility.

\footnotetext{
* Specific vendor and manufacturer names are explicitly mentioned only to accurately describe the test hardware. The use of vendor and manufacturer names does not imply an endorsement by the U.S. Government nor does it imply that the specified equipment is the best available.
}

3 of 24

American Institute of Aeronautics and Astronautics 


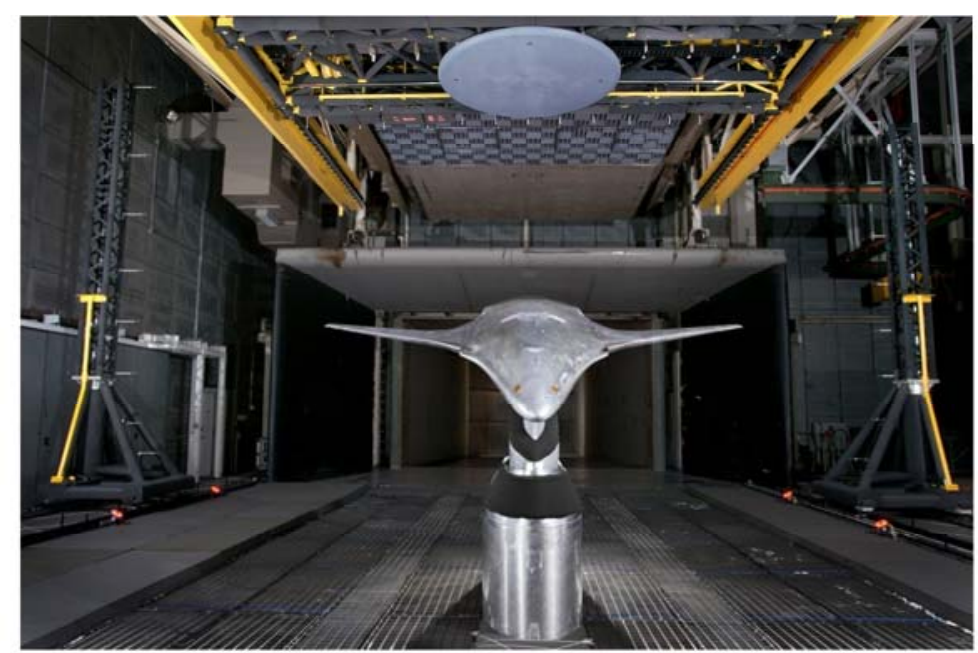

Figure 3. Overhead configuration of phased array panel with sideline towers shown for full-scale model testing.

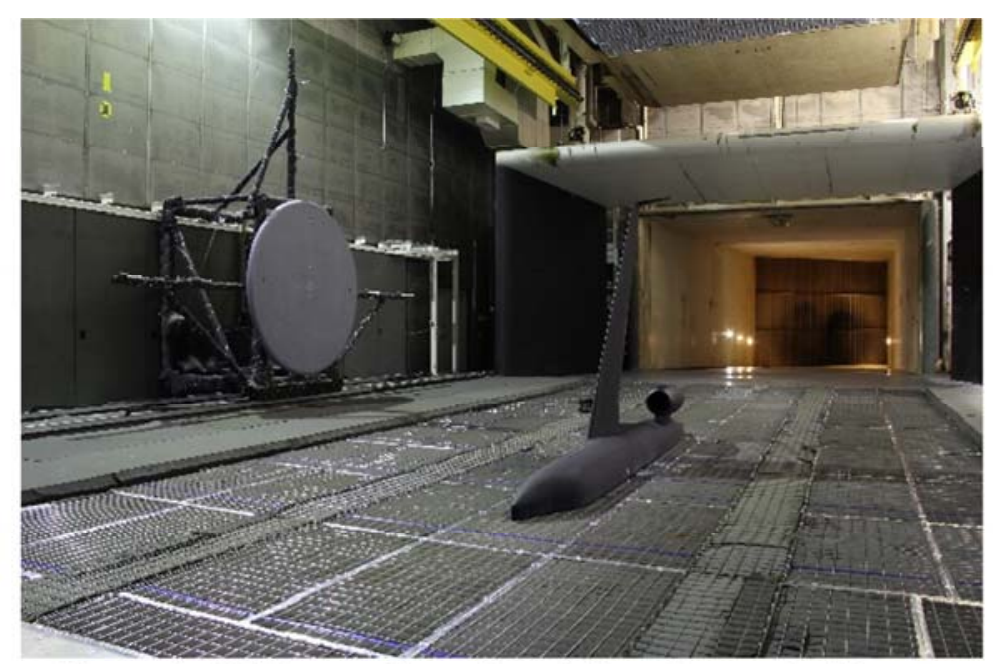

Figure 4. Sideline configuration of phased array, looking at pressure side of semi-span model.

\section{Instrumentation Suite}

Microphone Phased Array: The phased array fabricated for the $14 \times 22$ tunnel consists of 97 individual Bruel and Kjaer (B\&K) Model 4938 1/4-inch pressure field microphones attached to Model 2670 1/4-inch preamplifiers. The microphones are flush mounted (gap free) in a flat, double-layer fiberglass honeycomb panel with total diameter of 8.05 feet. The edge of the panel incorporates a 3-inch fillet around the circumference made of 10-pound foam board with a resin coating to smooth the surface. The rounded edge helps reduce sound diffraction effects for the outer microphones in the panel. The array is designed for an operational frequency range of approximately $1.5 \mathrm{kHz}$ to $80 \mathrm{kHz}$. This is achieved by using an irregular circular pattern of microphones comprised of 16 array arms with 6 microphones in each

4 of 24

American Institute of Aeronautics and Astronautics 
arm, as shown in Figure 5. One microphone is positioned in the center of the array. The maximum array aperture size (outermost microphone to outermost microphone) is 78.6 inches, yielding a solid collecting angle of 29.4 degrees at a working distance of 12.5 feet (from the array face to the centerline of the tunnel) when mounted in the ceiling of the test section. The collecting angle decreases to 21.2 degrees when the array is mounted on the side of the test section due to the longer working length of 17.5 feet in this orientation. These solid collecting angles are considered acceptable given the anticipated scales of full- and semi-span models tested in the facility. ${ }^{5}$ Appendix A contains a listing of the coordinates for all microphones mounted in the array.

Customized integral accelerometer and inclinometer systems were designed as part of the array panel construction for the monitoring of panel tilt and vibration during tunnel operation. The accelerometers / inclinometers are Analog Devices ADIS16209 MEMS sensors, controlled via an on-board microcontroller on the rear of the

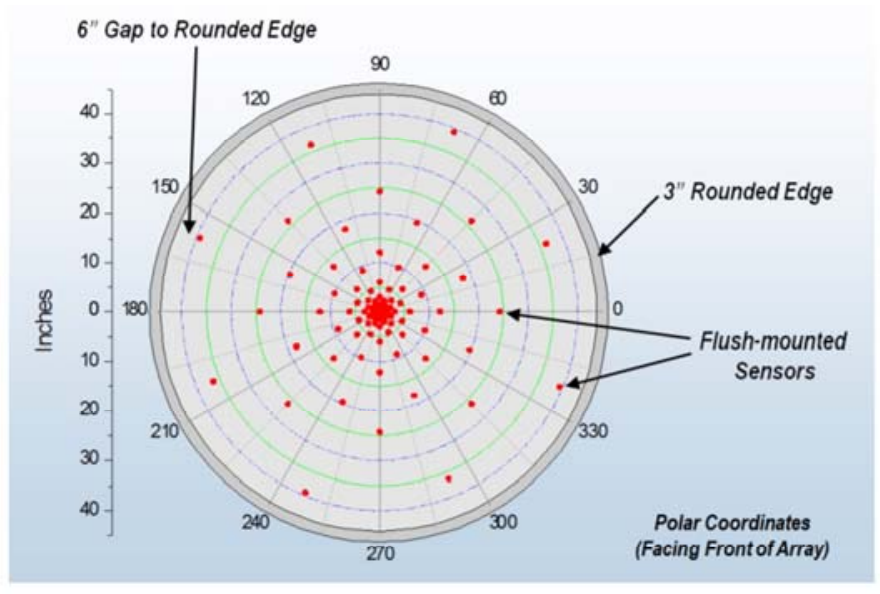

Figure 5. 14x22 tunnel phased array microphone pattern. array panel. The microcontroller digitizes the inclinometer data for transmission to the data acquisition system via a standard Ethernet connection. The analog accelerometer data is transmitted to the data acquisition system via 50 -ohm, RG-174 coaxial cables. Microphone signals from the array panel are transmitted to the data acquisition system using B\&K LEMO microphone cables that are also routed through available cable trays and conduits into distribution boxes in the control room. Depending on the application, the microphones can be powered by two different types of power supplies, namely B\&K Model 5935L dual-channel conditioning supplies or Model 2829 unity-gain, four-channel supplies.

Directivity Microphones: A total of 29 individual microphones can be mounted around the facility test section for use in full hemispherical characterization of noise directivity along flyover and sideline axes for various model configurations. The sensors are comprised of B\&K Model 4138 1/8-inch pressure field microphones attached to Model 2670 1/4-inch preamplifiers using 1/4-inch to $1 / 8$-inch adapters. The microphones are powered by B\&K Model 5935L dual-channel conditioning power supplies.

For the HWB testing that was conducted in the facility, the 44-foot linear traversing rails described in Section II were installed in two pairs on either side of the test section for mounting directivity microphones. Eight microphones were attached at specified $\mathrm{z}$ locations on open truss vertical towers constructed on platforms that attached to carriages on top of the rail pairs (see Figure 6 for a detailed photo of the arrangement and Appendix A for a listing of microphone coordinates). The towers were fitted with an electric winching system to lower and raise the towers for microphone calibration and replacement. The remaining 13 microphones were installed at specific y locations on the truss portion of the overhead traverse carriage and were positioned in the same plane as the microphone phased array, offset 62 inches downstream in $\mathrm{x}$ from the center of the array. The two pairs of linear traversing floor rails were synchronized with the overhead traverse such that all directivity microphones maintained constant relative streamwise locations in the tunnel. Note that similar microphone mountings can be made in the tunnel for directivity studies performed on other models.

5 of 24

American Institute of Aeronautics and Astronautics 


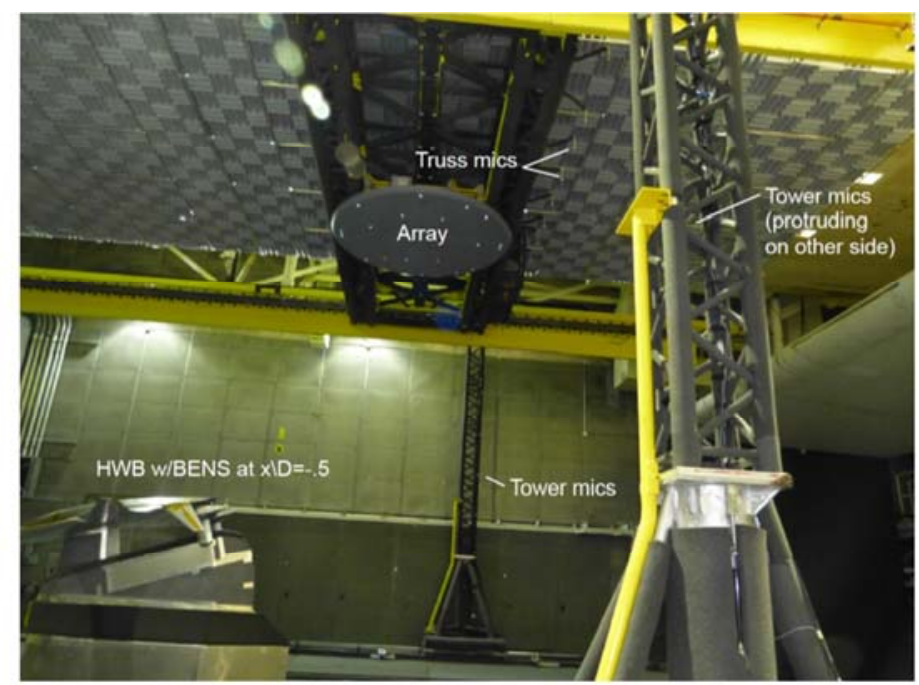

Figure 6. Detailed photo of individual directivity microphone installations around the test section.

\section{Calibration Procedures}

An extensive series of wind-off acoustic characterizations were performed in the $14 \times 22$ tunnel prior to use of the new instrumentation suite. The wind-off measurements included pyrotechnic detonation tests to check for spurious reflection paths to all microphone locations and speaker measurements to determine the reflection strength and reverberation time in the test section. Details of these measurements are discussed at length by Spalt et al. ${ }^{6}$ Additionally, individual microphone and full array calibration methods are applied as described below.

Array Microphones: Various array calibration methods and sensitivity studies were investigated as a precursor to installation of the new array in the facility. The studies examined the use of pseudo monopole noise sources positioned both external to the array panel and embedded in the panel to assess the best method for performing an in-situ calibration of the array. From these studies, it was determined that use of embedded sources on the panel was feasible. The sources are mounted in the array at approximate $90^{\circ}$ intervals referenced to the array center (Fig. 7) with an average radius of 3.34 feet. They are located as far as possible from array microphones without getting too close to the edge of the array in order to avoid possible edge reflections. Three different sources were tested to evaluate output characteristics and effects on the array microphones due to reflections from the speaker diaphragms. Ultimately, a Tymphany Peerless 4-ohm 25-mm tweeter was chosen due to its relatively flat output over the driven frequency range, low profile, and because it did not induce reflections

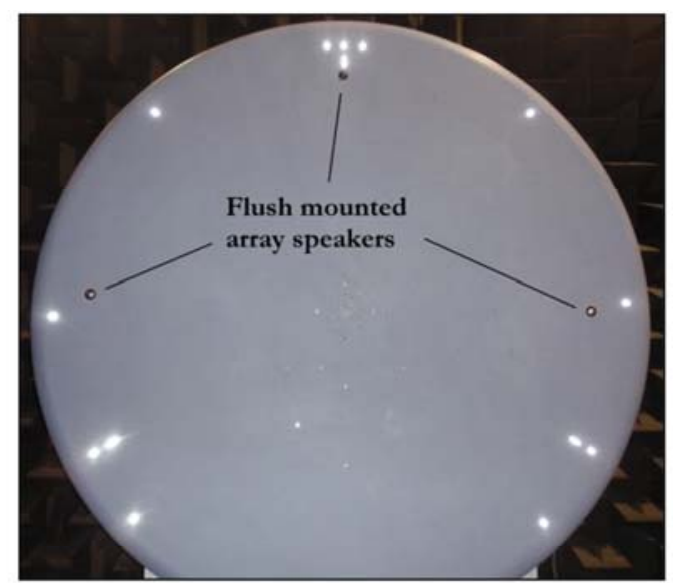

Figure 7. Flush-mounted array speakers installed in panel. Bright spots are photogrammetric targets on panel.

6 of 24

American Institute of Aeronautics and Astronautics 
at the array microphones (based on empirical testing). Three of the tweeters are embedded in the array such that the edges of the speaker sleeves are flush with the array face. Holes drilled in array face for speakers in their sleeves are $\sim 2.1$ inches in diameter.

When an in-situ calibration of the array is desired, each speaker is driven independently with filteredwhite-noise over a target frequency range. The following procedure was developed to identify microphone failures (at some point in the acquisition chain) and/or stray signals from baseline levels on individual microphones:

1. A $250-\mathrm{Hz}, 124-\mathrm{dB}$ pistonphone calibration is initially conducted on all microphones with necessary sensitivity adjustments made to equalize all of the channels to the same effective sensitivity.

2. The array is positioned at a designated location in the tunnel, chosen to avoid close reflecting objects. Each of the embedded sources is driven in turn using a defined level of input white noise ( 1 volt peak) over the target frequency band $(1-5 \mathrm{kHz})$. This procedure is repeated when averages are desired.

3. For each microphone / source combination, the pressure squared values (which have had external gains and sensitivities already accounted for) are summed over a frequency band of 1.5 to $4.9 \mathrm{kHz}$ and a sound pressure level (SPL) calculated in $\mathrm{dB}$ referenced to $2 \times 10^{-5}$ Pascals:

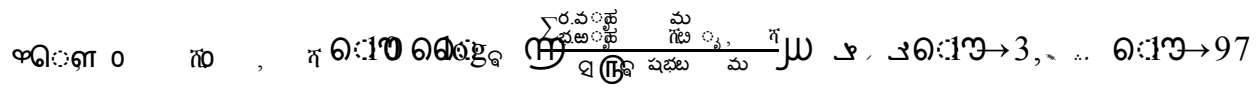

This defines the baseline $\mathrm{dB}$ value for each microphone / source combination.

4. At defined intervals when repeat calibrations are performed, each source is driven according to Step 2. For each source, the procedure in Step 3 applies with one difference: absolute output changes across the array due to atmospheric conditions and/or speaker changes must be allowed. Thus, for each source and microphone combination, the current calibration $\Delta \mathrm{dB}$ values have a reference $\Delta \mathrm{dB}$ subtracted from them. This reference $\Delta \mathrm{dB}$ is obtained by taking the difference of the medians of the inner 49 sensors of the current and baseline acquisitions:

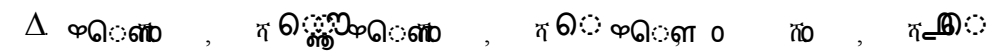

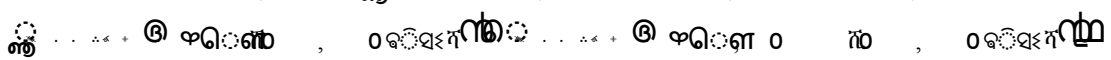

The inner 49 array microphones are located within an 9" diameter circle. Justifications for Eq. (2) are threefold: (1) taking the median avoids outliers, (2) using microphones in the center of the panel minimizes any possible edge effects, and (3) using the central microphones allows any directivity bias to be cancelled out between the three sources.

5. For each acquisition, a $\Delta \mathrm{dB}$ is generated for each source / microphone combination. The average of the three $\Delta \mathrm{dBs}$ can be taken to produce a single metric for each channel.

6. Each subsequent calibration produces a $\Delta \mathrm{dB}$ by subtracting the baseline levels from the current calibration. A running history of the $\Delta \mathrm{dB}$ levels is maintained to observe trends and to correct SPLs during post-processing.

A sample running history of $\Delta \mathrm{dB}$ levels for array microphones 1,2 , and 3 acquired over a one-month period during the HWB test campaign is shown in Figure 8. The $\Delta \mathrm{dB}$ deviations from the baseline level are shown for specific testing days, and is an average $\Delta \mathrm{dB}$ for the three independently driven sources on the array panel. Fig. 8 clearly shows that all three microphones stayed well within a $60.5 \mathrm{~dB}$ range, and no trends in deviation are observed in the data.

7 of 24

American Institute of Aeronautics and Astronautics 


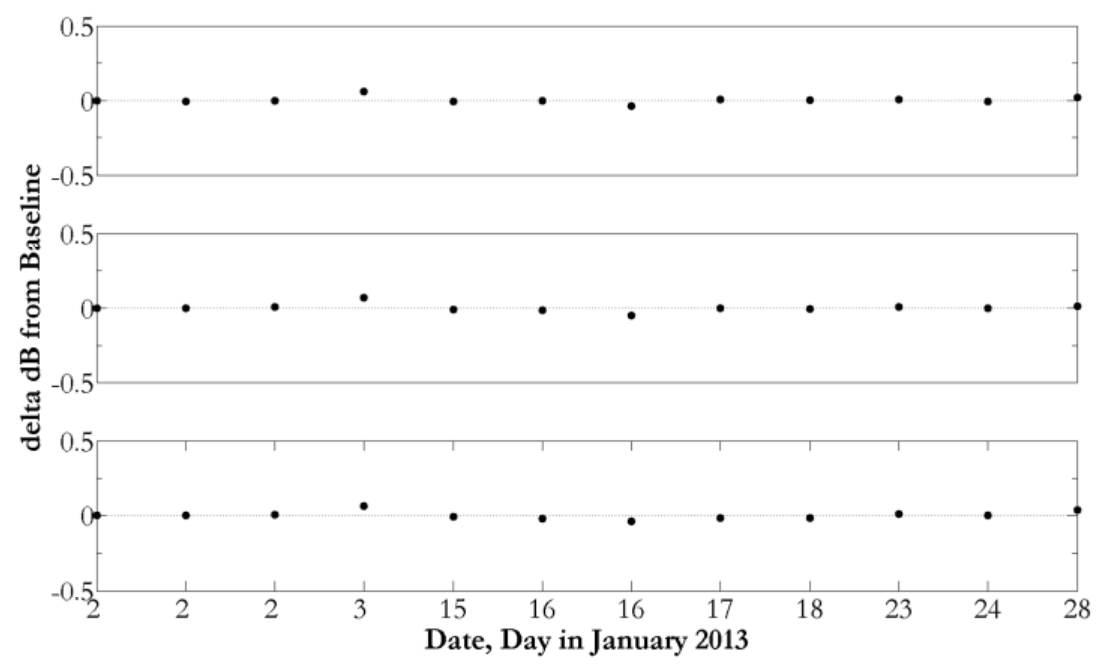

Figure 8. Daily variation in $\Delta \mathrm{dB}$ levels from baseline for microphones 1, 2 , and 3 (top, middle, and bottom traces, respectively) using the embedded speaker calibration technique.

In addition to the whole-array calibration procedure described above, all array microphones are calibrated at regular intervals using a charge injection technique. ${ }^{7}$ Calibrations are performed on the microphones by applying a broadband white noise signal with known RMS voltage to all microphone preamplifiers (bypassing the diaphragms) and recording the output signals on the data acquisition system. Daily variations in the injection calibration output signal voltages are compensated by either adjusting the gains on the microphone power supplies or by applying inverse gain settings on the appropriate signal conditioner channel in the data system. Thus, a constant effective sensitivity for all of the microphones is maintained until a new pistonphone calibration can be performed.

Directivity Microphones: Calibration of individual directivity microphones is achieved using a standard pistonphone to equalize the sensitivities of the sensors on a regular basis. In addition, charge injection calibrations are performed in the same manner as for the phased array microphones by applying a broadband white noise signal with known RMS voltage to all preamplifiers and recording the output signals on the data acquisition system. Daily variations in the injection calibration output signal voltages are compensated at the power supply and/or the signal conditioning stage. Repeat pistonphone calibrations were conducted at regular intervals during testing.

\section{Data Acquisition and Analysis}

A highly distributed data acquisition and analysis system was assembled for the array and sideline microphone systems using commercially available hardware. Block diagrams of the major components are shown in Figures 9 through 11 with details of individual components described below.

Data Acquisition System: The data acquisition system has a total capacity of 192 channels and is constructed around National Instruments PXI-6120 high speed, synchronous sampling digitizers. The digitizers are housed in three separate chassis each containing an embedded client computer with local disk storage. Signal conditioning of all microphone channels is achieved using a Precision Filters, Inc.,

8 of 24

American Institute of Aeronautics and Astronautics 
Model 28000 system populated with PF-28608 bandpass filter cards (8 channels per card with an approximate roll-off of $28 \mathrm{~dB}$ /octave per channel). The entire data system is controlled from a master computer which communicates with the various clients using high speed Ethernet configured in a 5-subnet LAN (see Figure 10). The process controller also provides tightly synched clock and trigger functions to each client via a PXI-1033 chassis using PXI-6653 master timing modules. A National Instruments Labview ${ }^{\circledR}$ program is used for command and control of all of the hardware components of the data system, the facility overhead traverse system, and the Aerotech linear rail system. The acquisition program also interfaces with the wind tunnel data system and array inclinometers to capture relevant tunnel, model, and array orientation parameters during an acquisition cycle. Acquired microphone time history data are stored on

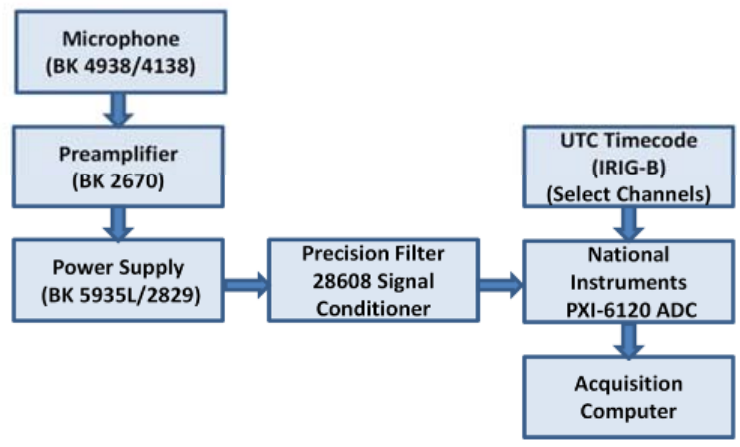

Figure 9. Block Diagram of Data Acquisition System.

high capacity network-attached storage (NAS) devices as a series of individual raw binary data files (one file per acquisition channel). The nominal acquisition window length is 30 seconds. Simultaneous sampling rates are dependent on the application (the rate for the HWB test campaign was $250 \mathrm{kHz}$ while it was lowered to $200 \mathrm{kHz}$ for the Gulfstream airframe noise test). The signals are bandpass filtered nominally from $400 \mathrm{~Hz}-100 \mathrm{kHz}$. Finally, an IRIG-B timecode signal is acquired on one acquisition channel in each embedded client as a sanity check to ensure synchronization of the system is maintained.

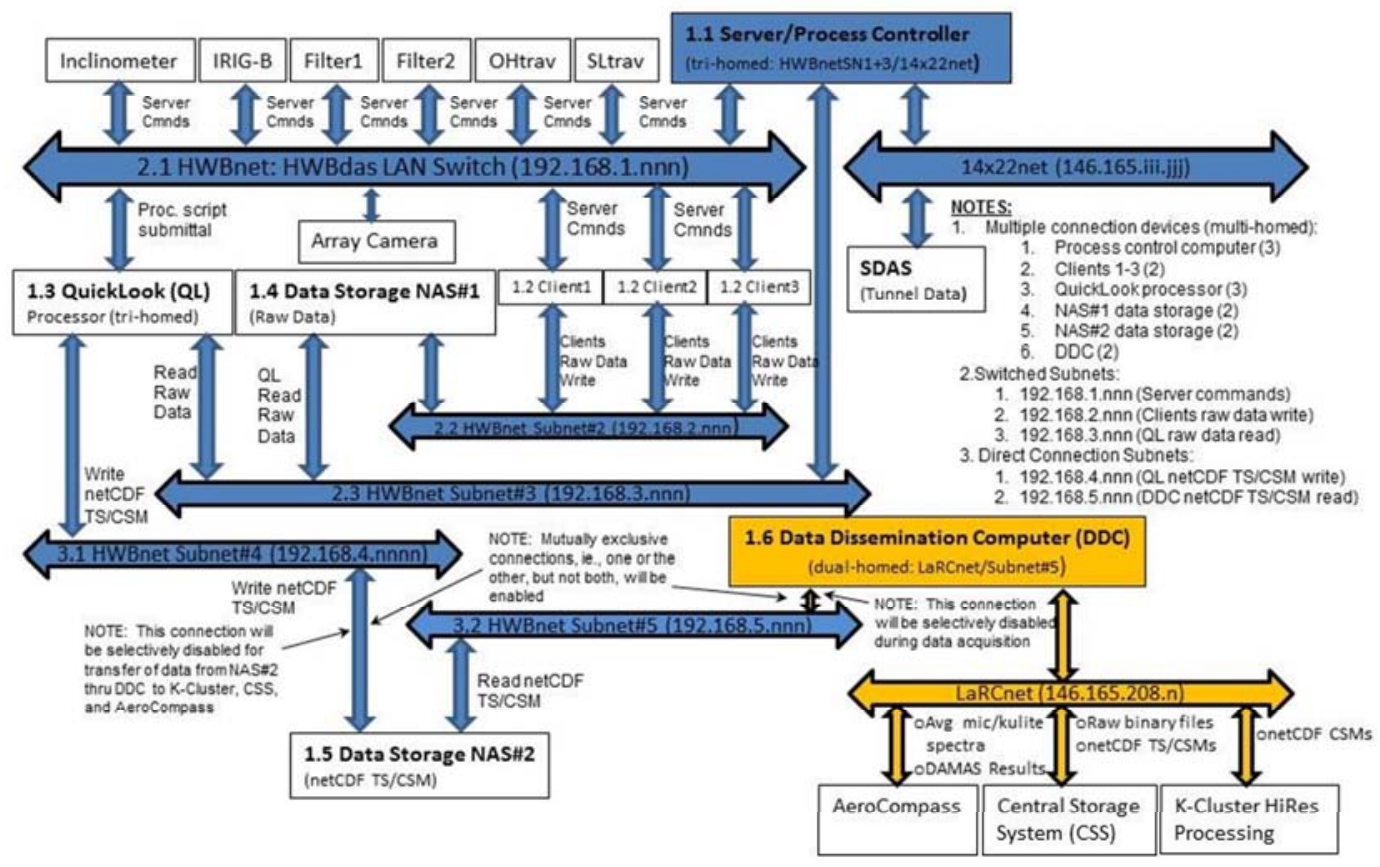

Figure 10. LAN communication subnets for data acquisition system.

9 of 24

American Institute of Aeronautics and Astronautics 
Data Reduction System: The data reduction system consists of a distributed set of computers for preprocessing of array and individual microphone data coupled with the NASA Langley mid-level compute capability $\mathrm{K}$ cluster for detailed analysis. The block diagram of this configuration is shown in Figure 11. The preprocessing operations performed on the microphone data include the following:

- Conversion of raw binary data files generated by the acquisition system into Network Common Data Format (NetCDF) files ${ }^{8}$ containing not only the time history data but also metadata (data acquisition settings and tunnel / model parameters) stored in the file headers.

- Generation of separate Cross Spectral Matrix (CSM) files in engineering units for both the phased array and directivity microphones. A Mathworks Matlab® code utilizing a Graphical Processing Unit (GPU)-based parallel computing toolbox is utilized for the generation of the CSM files to greatly improve the efficiency of the code. A number of corrections and calibrations are applied during CSM generation including microphone frequency response functions and microphone sensitivity calibration adjustments.

- Archiving of the CSM files for further processing on the Langley K cluster.

The details of the computations and corrections listed above are discussed by Bahr. ${ }^{9}$ Detailed analysis of array data is performed using standard frequency-domain delay and sum beamforming coupled with the DAMAS deconvolution algorithm for generation of final noise source map presentations and integrated spectra. ${ }^{10-11}$ A customized version of the DAMAS algorithm, called Unified DAMAS (UDAMAS), combining aspects of both the DAMAS and DAMAS-C algorithms, is executed on the K cluster for this purpose. The UDAMAS code is parallelized to take advantage of the multi-core capabilities of the cluster to greatly improve execution times during processing. Beamformed and deconvolved source presentation maps for standard 1/12-octave or 1/3-octave bands spanning the frequency range of the array can be generated with full corrections applied for shear layer amplitude and ray path effects. From these, integrated SPL's can be generated for various sub-regions on the maps.

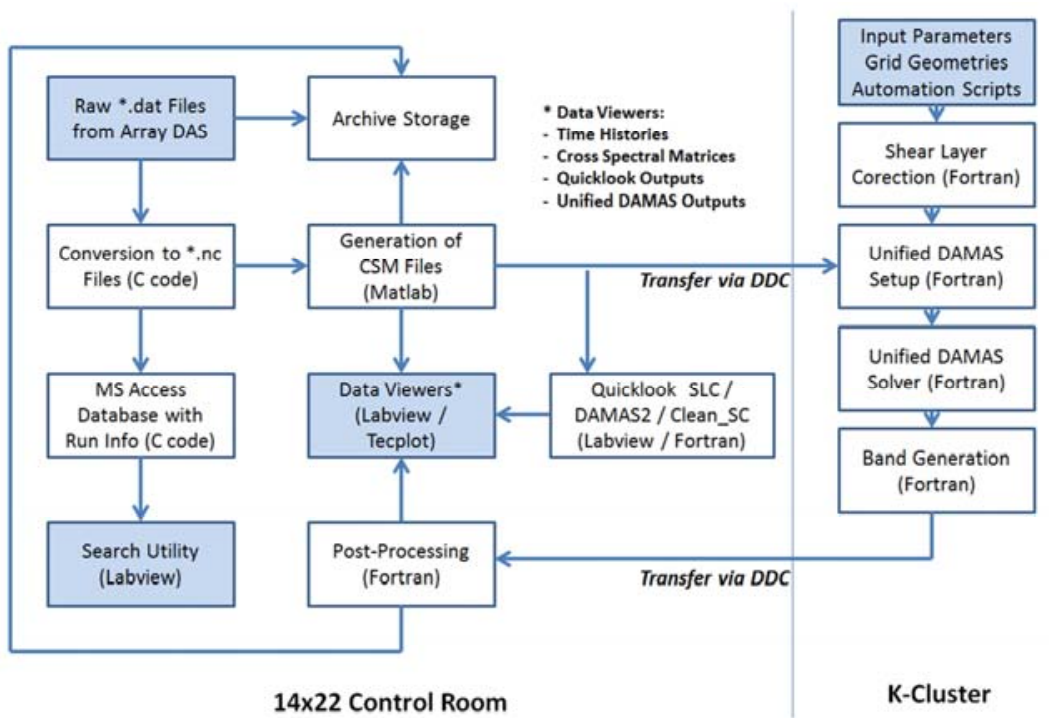

Figure 11. Phased array / directivity microphone data reduction system. A Data Dissemination Computer (DDC) provides the interface between the tunnel and the K-Cluster.

10 of 24

American Institute of Aeronautics and Astronautics 


\section{Performance Analysis}

An in-depth performance analysis was conducted as part of the array design described in Section III. The analysis includes: (1) computation of the coarray function to determine a figure of merit for the geometrical layout of the microphones in the array, and (2) computation of the array point spread function (PSF) as a function of frequency to examine beamwidths and sidelobe locations and strengths.

Coarray Analysis: The coarray function, introduced by Haubrich ${ }^{12}$ and described by Underbrink, ${ }^{13}$ provides a convenient method of computing a figure of merit (FOM) for the array that quantifies the ability to maximize sidelobe reduction and minimize spatial aliasing. In short, for an array aperture with $m_{0}$ microphones at locations $\dot{\bullet}$, a set of geometric points can be computed using

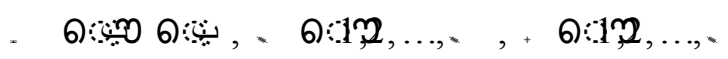

where - contains the complete ensemble of vector spacings between coordinates of array microphones. There are a total of . ${ }^{\text {का }}$ possible vectors in = with . of these being zero; therefore, the maximum number of vectors that can exist in the coarray is

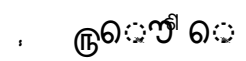

A FOM can be created that represents the ratio of the actual number of unique vector spacings in the array, $P$, to , 다

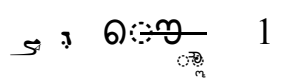

An ideal array pattern would have a FOM of unity, where all of the vector spacings computed via Eqn. (3) are unique, thus maximizing the ability of the array to spatially filter signals and minimizing the sidelobe strengths in the PSF for the array. Figure 12 depicts the coarray function for the array design shown in Fig. 5. Each symbol represents one vector spacing as computed by Eqn. (3), with the two different colored symbols representing reciprocal values (i.e., $m-n$ and $n-m$ combinations in Eqn. (3)). Vector spacings are considered non-overlapping for an $m, n$ pair of microphones if the individual $\mathrm{x}$ and $\mathrm{y}$ coordinates each differ by a minimum of $1 \times 10^{-4}$ inches. For the pattern of microphones chosen for the array, there are 9033 non-overlapping symbols shown in Fig. 12. Consequently, the FOM as computed by Eqn. (5) is 0.96 . This FOM indicates that the array should have very acceptable spatial filtering characteristics and minimized array response sidelobes with respect to the main beam of the array.

Array PSF: Computation of the PSF (also known as the array response) is the primary analysis tool used to ascertain the

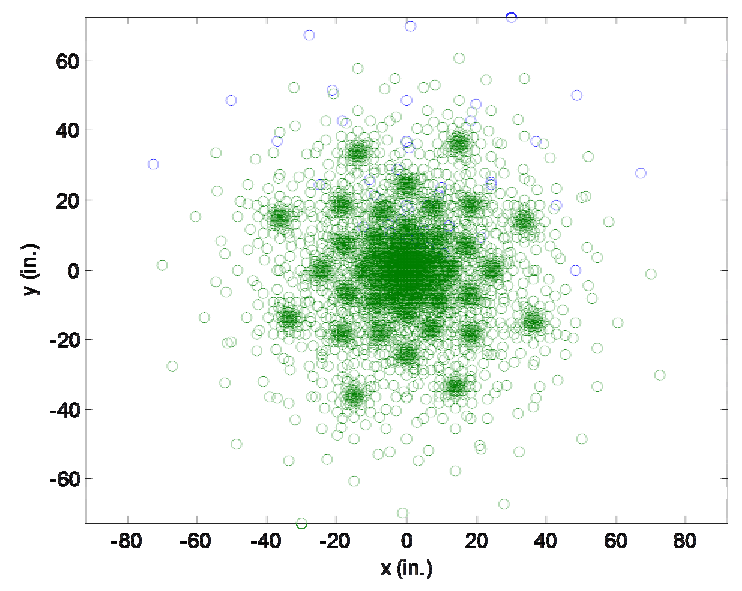

Figure 12. Coarray function for array pattern shown in Fig. 5. FOM =0.96.

11 of 24

American Institute of Aeronautics and Astronautics 
effectiveness of a particular design. ${ }^{13-14}$ The analysis is based on the assumption that one or more simulated uncorrelated monopole sources are located at defined locations with respect to the center of the array. In order to compute the PSF, in the frequency domain one can model the array Cross Spectral Matrix (CSM) for a single source located at $\dot{*}$ referenced to the center of the array for radial frequency $\omega$ (see references 10 and 11) as

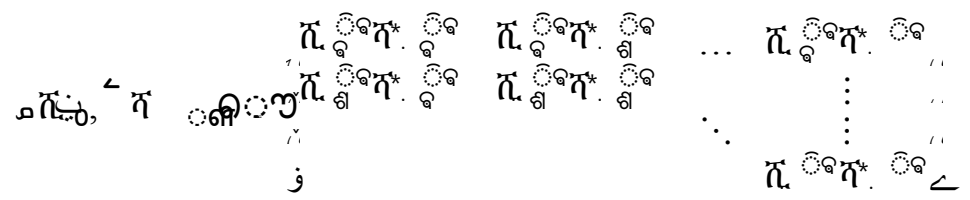

where $X$ is the mean squared pressure of the simulated source at $\dot{0}, m_{0}$ is the number of microphones in the array, and $e_{m}$ is the scaled phase delay for microphone $m$ ( $e_{m}$ being a component of the beamform steering vector. '), represented as

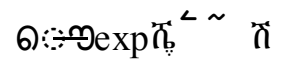

where $r_{m}$ and $r_{c}$ are the distances from the source to the $\mathrm{m}^{\text {th }}$ microphone and center of the array respectively, and $\tau_{m}$ is the propagation time from the source to microphone $m$. The natural response of the array to the source can be computed using the standard beamform equation modified to include the modeled CSM as

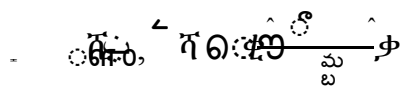

where ${ }^{\wedge}$ is the steering vector with components computed using Eqn. (7) for the source at $\dot{-0}$ assuming an array measurement location $\dot{*}$. If array shading is to be performed, Eqn. (8) can be modified to include a row matrix . containing individual microphone weights $\stackrel{\leftrightarrow}{\leftrightarrow}$ as

$$
\text { ) }
$$

To compute the PSF for the array, a single source is simulated in front of the center of the array at a given working distance using Eqn. (6), followed by Eqn. (8) or (9) computed over a defined discrete measurement grid centered about the source. The PSF is traditionally presented as a decibel noise contour plot normalized to the peak value of $Y$ at the location of the source.

Figure 13 illustrates a series of PSF's for the ceiling-mounted configuration of the array in the $14 \times 22$ tunnel. A single synthetic source is positioned 12.5 feet in front of the array and operated at frequencies of $5,10,20,40$, and $80 \mathrm{kHz}$. The array shading algorithm described in Appendix B is used to generate the frequency-dependent row matrix . in Eqn. (9) containing individual microphone weights. Examining panels (b) through (f) in the figure, the central main beam of the array response is clearly visible and exhibits a frequency-independent beamwidth of approximately 6 inches over a wide frequency range. This is confirmed in panel (a) in the figure where the $3-\mathrm{dB}$ beamwidth computed as a function of frequency for both the unshaded array (i.e., unity weights in .. ) and the shaded array are compared. Finally, the sidelobes as shown in panels (b) through (f) are uniformly distributed about the main beam, with all sidelobes exhibiting SPL levels at least $5 \mathrm{~dB}$ lower than the main beam within the $20 \mathrm{x} 20$-foot viewing area of the measurement grid.

\section{2 of 24}

American Institute of Aeronautics and Astronautics 

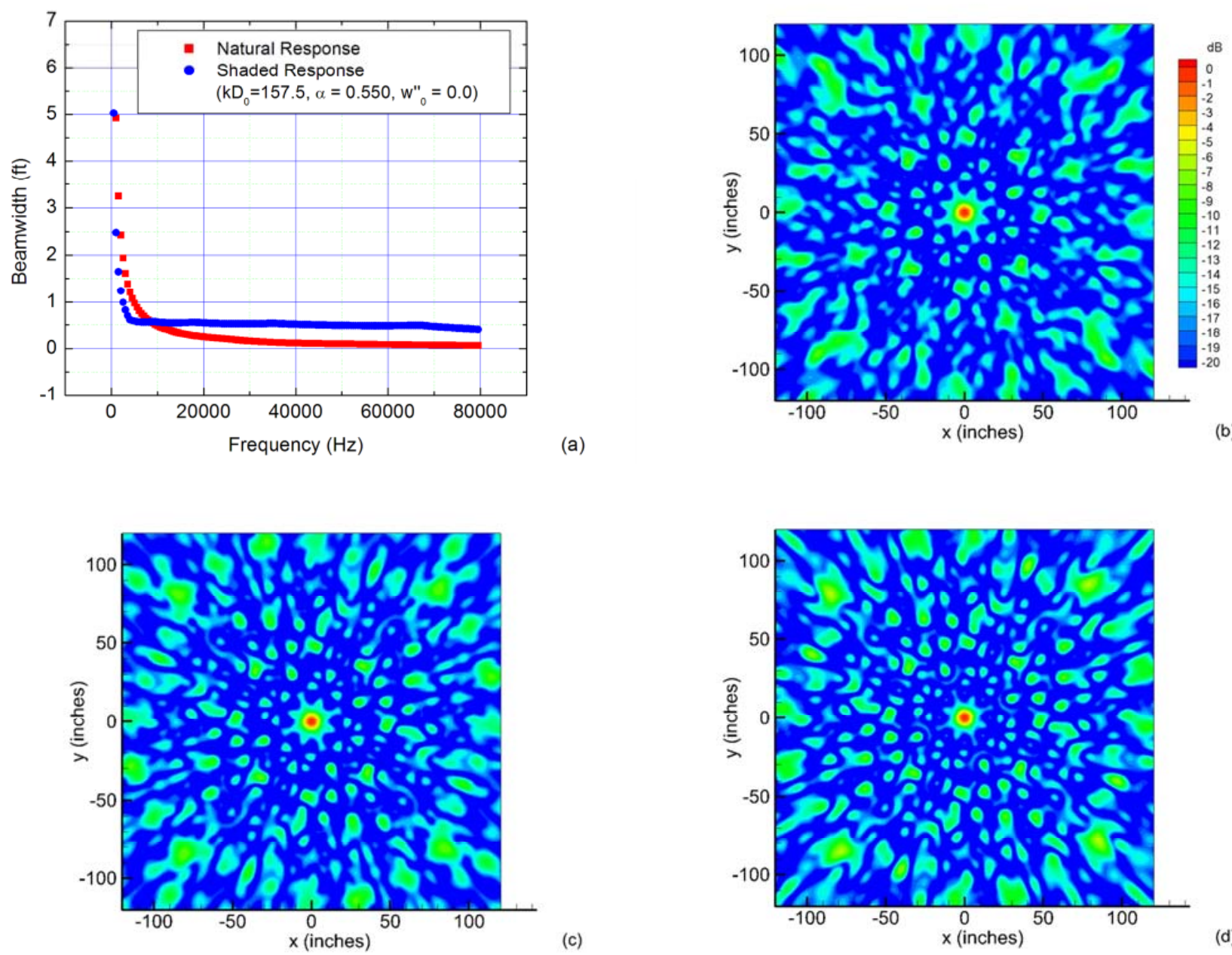

(d)
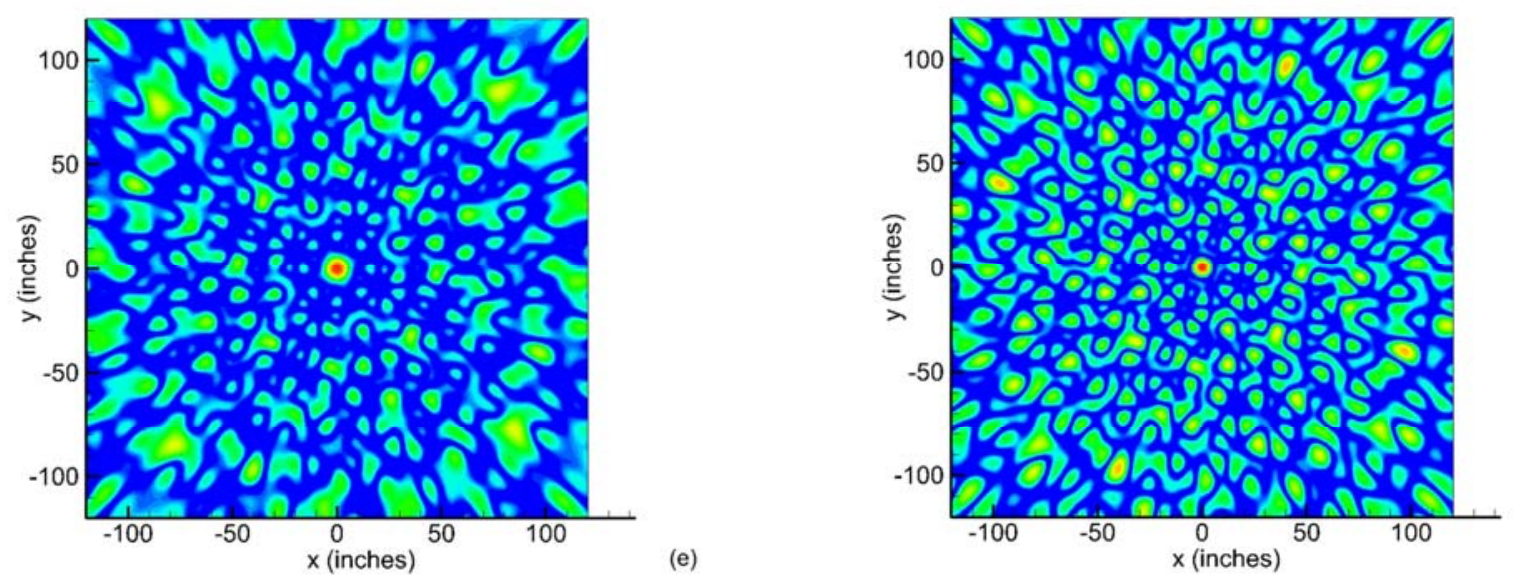

Figure 13. Shaded response of array for ceiling mount configuration.

(a) - Comparison of 3-dB beamwidth for natural and shaded responses

(b) through (f) - Shaded responses for $5,10,20,40$, and $80 \mathrm{kHz}$ monopole source, respectively, positioned 12.5 feet in front of array

13 of 24

American Institute of Aeronautics and Astronautics 


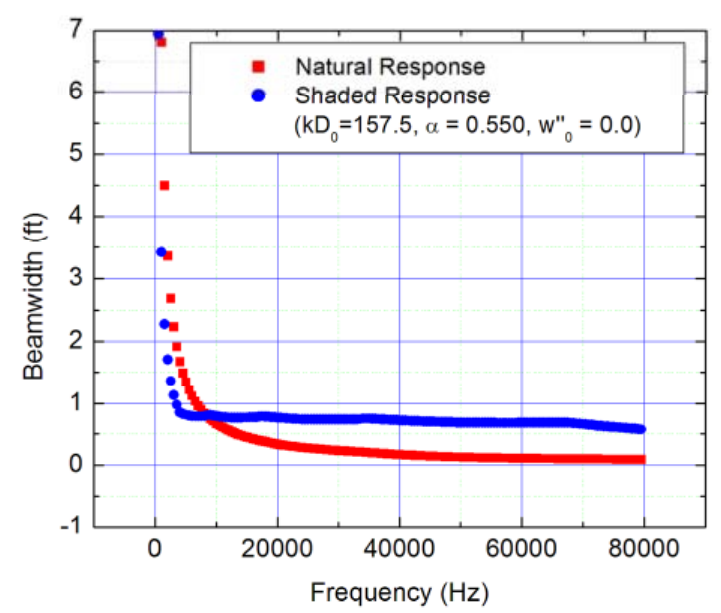

(a)
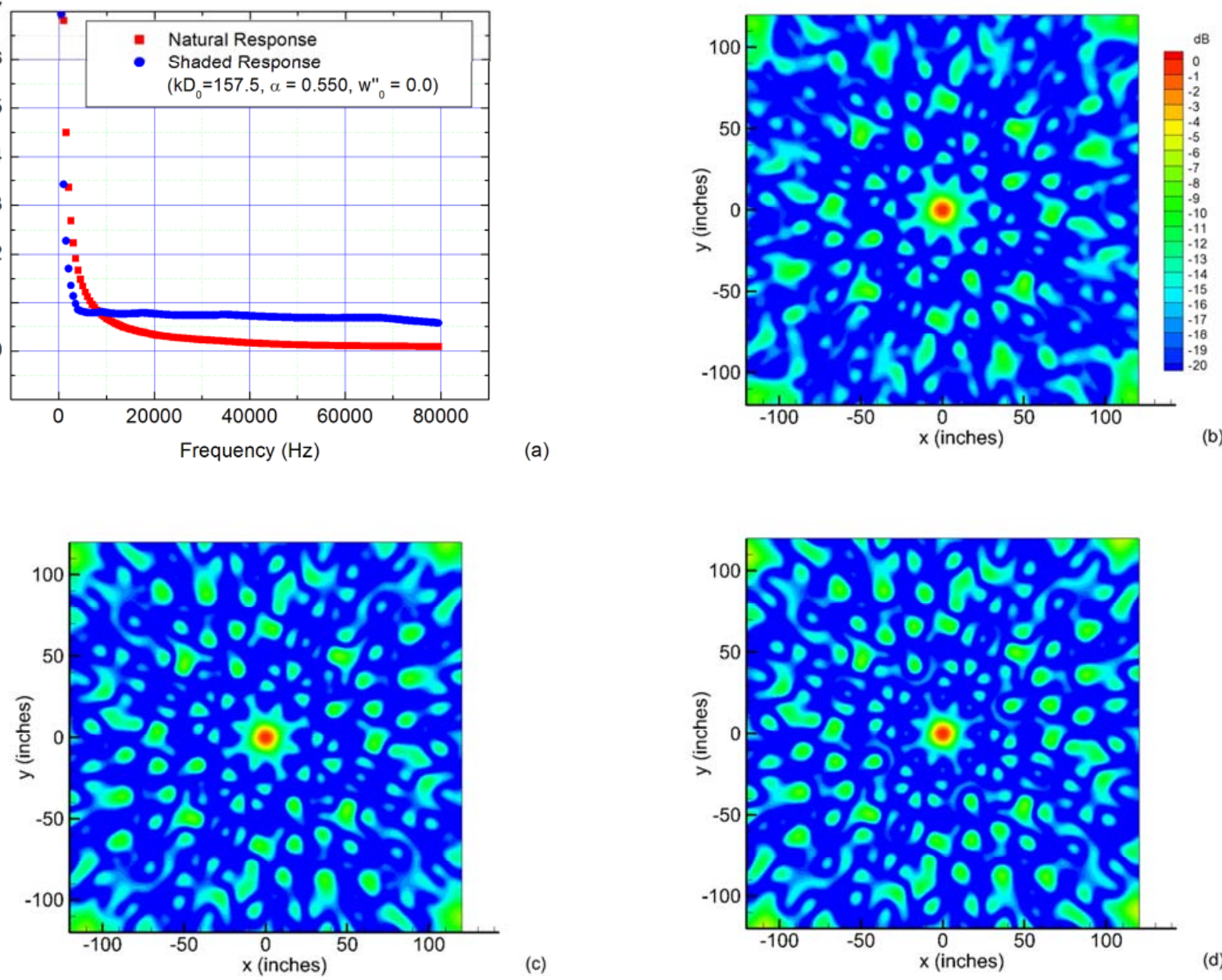

(d)
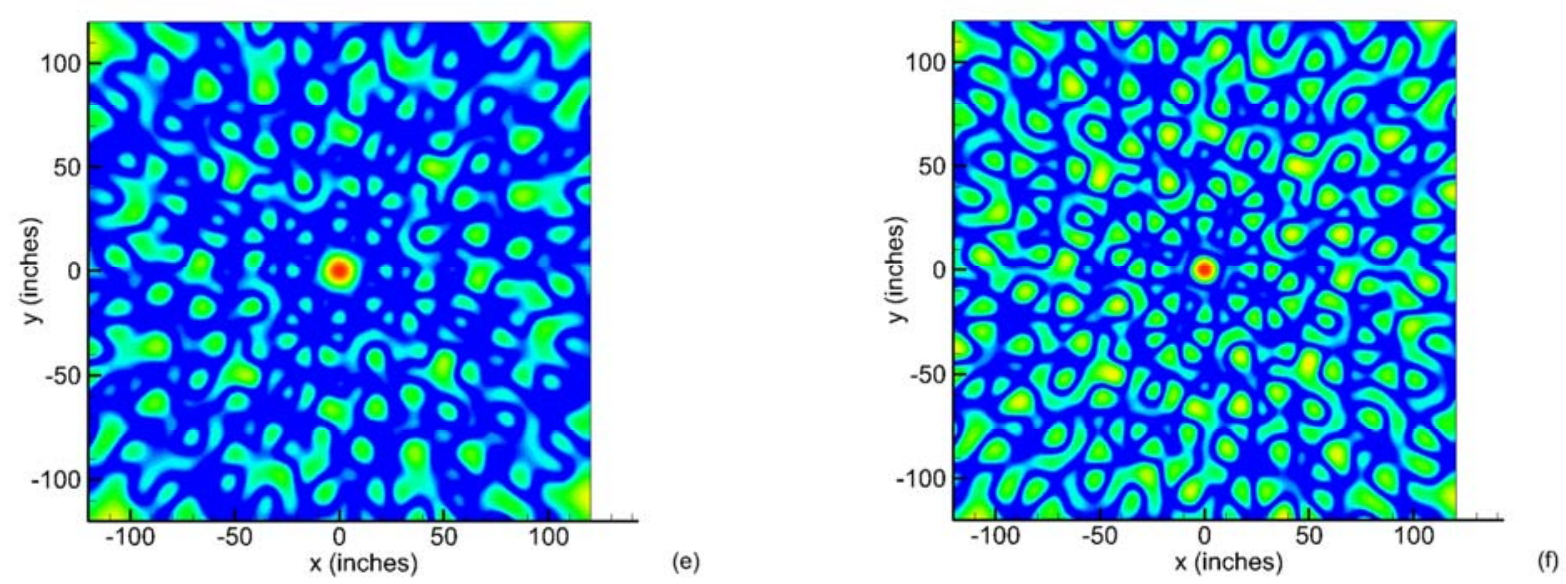

Figure 14. Shaded response of array for sideline mount configuration.

(a) - Comparison of 3-dB beamwidth for natural and shaded responses

(b) through (f) - Shaded responses for 5, 10, 20, 40, and $80 \mathrm{kHz}$ monopole source, respectively, positioned $\mathbf{1 7 . 5}$ feet in front of array

14 of 24

American Institute of Aeronautics and Astronautics 
Figure 14 illustrates similar PSF presentations for the sideline-mounted configuration of the array in the facility. Due to the longer working distance for the sideline configuration, the synthetic source has been repositioned to be 17.5 feet in front of the array and operated at frequencies of 5, 10, 20, 40, and $80 \mathrm{kHz}$. As in Fig. 13, the array shading algorithm described in Appendix B is used to generate the frequency-dependent row matrix . . Examining panels (b) through (f) in the figure, the central main beam and sidelobe structures are now larger due to the reduced solid collecting angle of the array. The PSF's exhibit a frequency-independent beamwidth of approximately 8 inches. This is confirmed in panel (a) in the figure where the 3-dB beamwidth computed as a function of frequency for both the unshaded array (i.e., unity weights in . ) and the shaded array are compared. As in Fig. 13, the sidelobes as shown in panels (b) through (f) of Fig. 14 are uniformly distributed about the main beam, with sidelobe levels at least $5 \mathrm{~dB}$ lower than the main beam across the viewing area of the measurement grid.

\section{Data Product Examples}

Brief examples of data products generated by the instrumentation suite in the $14 \times 22$ tunnel are shown in Figures 15 through 17. Figure 15 illustrates the types of directivity information that can be acquired in the facility for full-span models using the arrangement of microphones shown in Fig. 6. Note that the HWB models in the upper left and upper right panels of Fig. 15 are shown inverted due to the need to install the phased array and directivity microphones in the ceiling of the test section. The lower panels in the figure show the transformations necessary to create a proper ground plane-oriented hemispherical directivity function for the vehicle. Detailed noise scaling and community noise impact data can be extracted from the results shown in Fig. 15. Extensive HWB directivity data obtained with the instrumentation suite are discussed in detail by Hutcheson et al. ${ }^{15}$, Doty, et al ${ }^{16}$, and Burley et al. ${ }^{17}$

Figure 16 illustrates a sample airframe noise source location map for the pressure side of the HWB model. Unified DAMAS with full shear layer correction was utilized to generate this high resolution image of the noise sources created by the drooped leading edge, the nose gear, and the main gear components of the model undercarriage. Similar noise map presentations are possible when the array is mounted in a sideline configuration. In Figure 17, the pressure side of the Gulfstream airframe model is visible with both standard beamform and Unified DAMAS presentations shown. The noise generated by the inboard flap edge and main landing gear are clearly visible in the DAMAS presentation in Fig. 17. In Ref. 3, Khorrami et al. discuss in detail the data obtained with the array mounted on the side of the test section for flyover viewing of the model for multiple observer angles and model configurations.

\section{Summary}

A new aeroacoustic measurement capability has been developed for use in open-jet testing in the $14 \times 22$ tunnel. The capability includes a 97 -microphone phased array system that can be mounted in the ceiling of the facility or along either of two sides of the test section. The capability also includes an ensemble of individual microphones that can be positioned at defined locations around the test section for directivity studies. Facility upgrades were performed including the installation of a two-axis overhead traverse system and multiple floor-based linear traversing rails to facilitate scanning of the phased array and directivity microphones. Customized data acquisition and reduction systems were built to handle the large volumes of data generated by the array and directivity microphones. Performance analysis of the array using a coarray FOM and synthetic PSF's using monopole sources show that the array design is adequate for its intended purpose in the facility. The instrumentation suite represents a significant augmentation to the measurement capability of the $14 \times 22$ tunnel and will provide a useful tool for researchers engaged in aeroacoustic testing in the facility for the foreseeable future.

15 of 24

American Institute of Aeronautics and Astronautics 

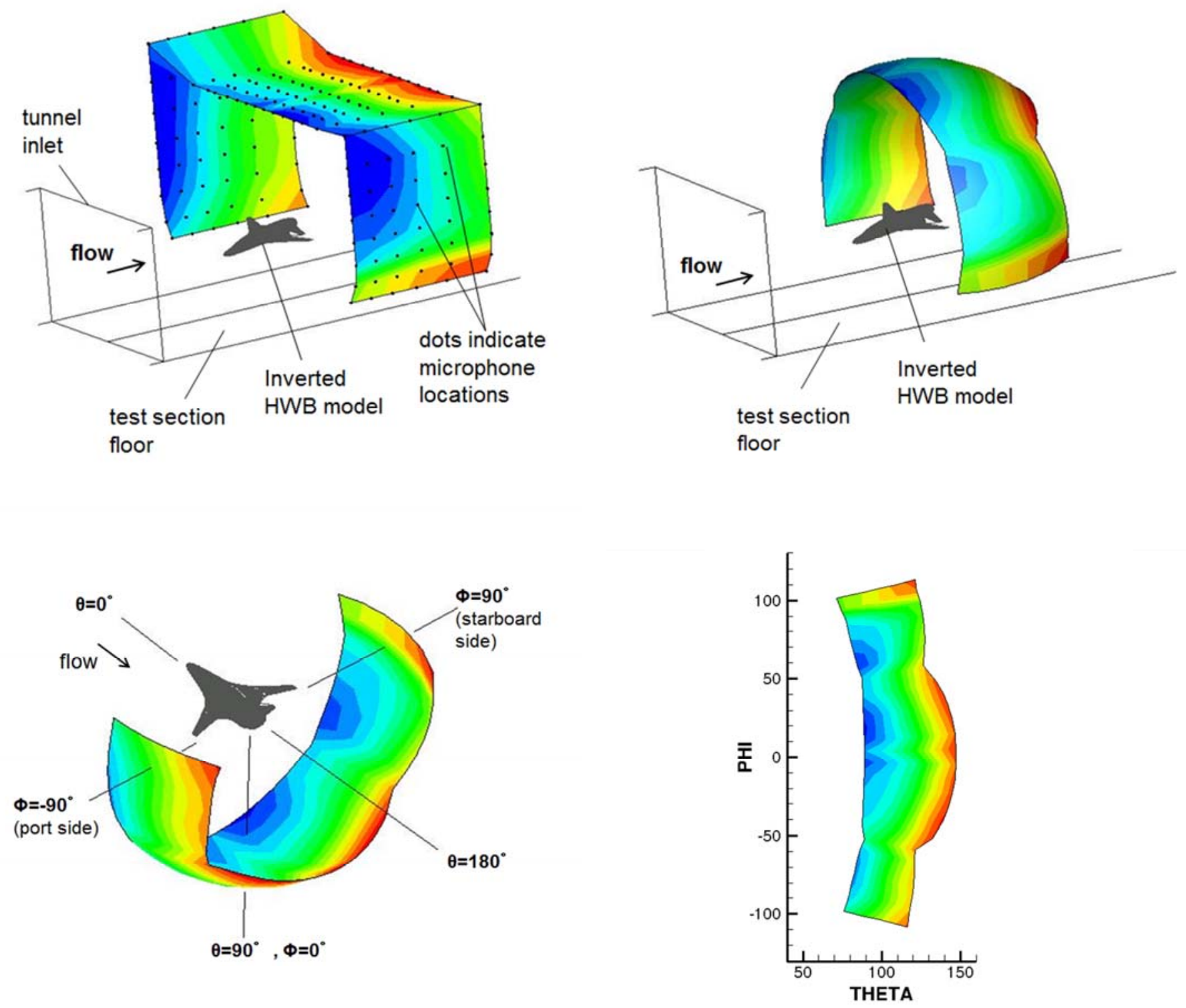

Figure 15. Hemispherical directivity measurements in the 14x22 tunnel for the HWB test campaign.

Upper Left - Corrected SPL contour levels over area traversed by directivity microphones

Upper Right - Corresponding SPL levels on hemisphere

Lower Left - Model rotated upright with hemisphere toward ground

Lower Right - Unfolded hemispherical directivity

16 of 24

American Institute of Aeronautics and Astronautics 


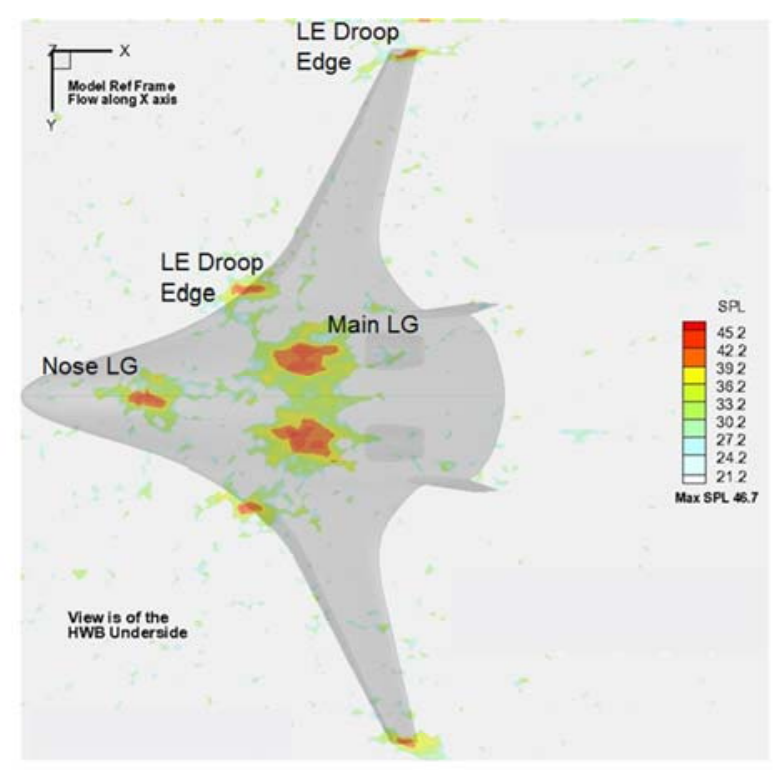

Figure 16. UDAMAS noise contour presentation for the pressure side of the HWB model.
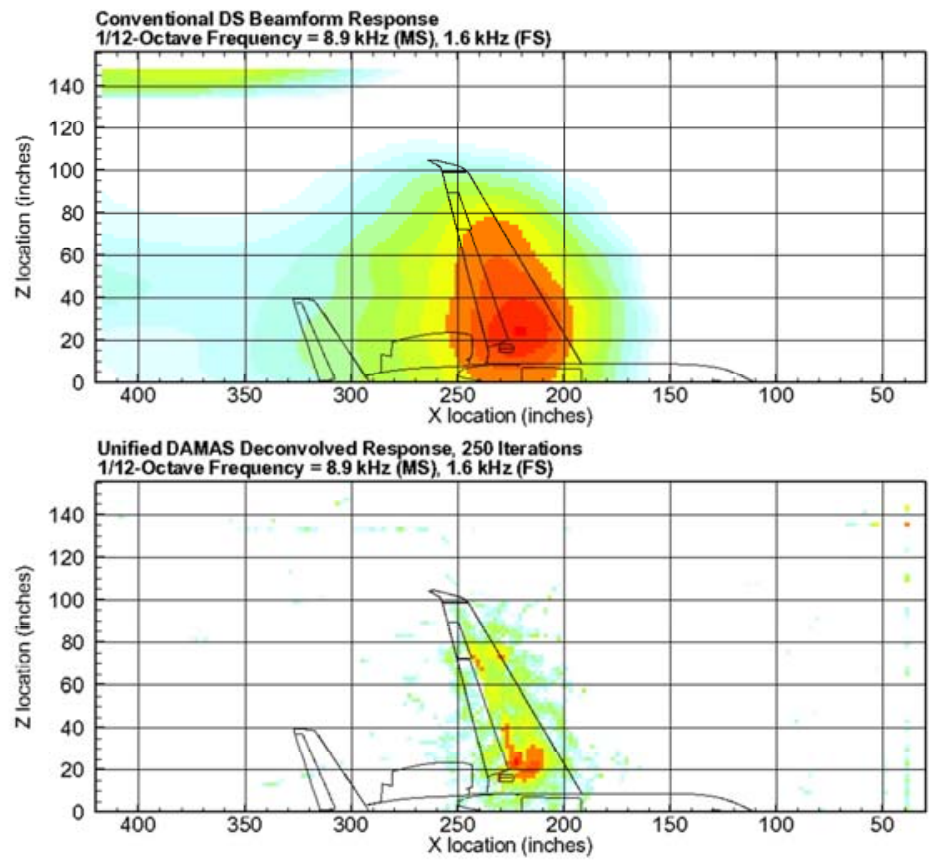

Figure 17. Conventional beamform and UDAMAS noise contour presentations for the Gulfstream airframe model.

17 of 24

American Institute of Aeronautics and Astronautics 


\section{Acknowledgments}

The authors gratefully acknowledge Florence Hutcheson and Casey Burley of the NASA Langley Aeroacoustics Branch for providing the directivity data shown in Fig. 15, and Gerald Plassman of the National Institute of Aerospace for providing the Unified DAMAS presentation shown in Fig. 16 and for providing details of the array shading algorithm shown in Appendix B. The authors also acknowledge the contributions of Karl Wiedemann of Analytical Services and Materials, Inc., for his excellent support and coding of the UDAMAS code. Finally, the authors acknowledge the outstanding work and dedication of the employees of Jacobs Engineering and the Langley 14x22 tunnel (facility managers, engineers, and technicians) in installing the infrastructure needed to support the instrumentation suite in the facility. This work was sponsored by the NASA Environmentally Responsible Aviation Project and the NASA Aeronautics Test Program.

\section{References}

${ }^{1}$ Collier, F. S., "Environmentally Responsible Aviation (ERA) Project," oral presentation, NASA Fundamental Aeronautics Program, Third Annual Meeting, Atlanta, GA, Sept., 2009.

${ }^{2}$ Gatlin, G. M., Vicroy, D. D., and Carter, M. B., "Experimental Investigation of the Low-Speed Aerodynamic Characteristics of a 5.8-Percent Scale Hybrid Wing Body Configuration," AIAA Paper 2012-2669, 30 ${ }^{\text {th }}$ AIAA Applied Aerodynamics Conference, New Orleans, LA, June, 2012.

${ }^{3}$ Khorrami, M. R., Humphreys, W. M., Jr., Lockard, D. P., and Ravetta, P. A., "Aeroacoustic Evaluation of Flap and Landing Gear Noise Reduction Concepts," $20^{\text {th }}$ AIAA/CEAS Aeroacoustics Conference, Atlanta, GA, June, 2014.

${ }^{4}$ Heath, S. L., et al., "Hybrid Wing Body Aircraft Acoustic Test Preparations and Facility Upgrades," AIAA Paper 2013-2623, 28 ${ }^{\text {th }}$ AIAA Aerodynamic Measurement Technology, Ground Testing, and Flight Testing Conference, San Diego, CA, June, 2013.

${ }^{5}$ Brooks, T. F., and Humphreys, W. M., Jr., "Effect of Directional Array Size on the Measurement of Airframe Noise Components," AIAA Paper 99-1958, $5^{\text {th }}$ AIAA/CEAS Aeroacoustics Conference, Bellevue, WA, May, 1999.

${ }^{6}$ Spalt, T. B., Brooks, T. F., Bahr, C. J, Plassman, G. E., Becker, L. E., and Stead, D. J., "Calibrations of Langley's 14- by 22-Foot Subsonic Wind Tunnel in Acoustic Configuration," $20^{\text {th }}$ AIAA/CEAS Aeroacoustics Conference, Atlanta, GA, June, 2014.

${ }^{7}$ Frederiksen, E., "Microphone Monitoring by Charge Injection Calibration," Journal of the Acoustical Society of America, Volume 96, Number 5, pp. 3271, 1994.

${ }^{8} \mathrm{NetCDF}$ software and documentation can be found at http://www.unidata.ucar.edu/software/netcdf/.

${ }^{9}$ Bahr C. J., Brooks, T. F., Humphreys, W. M., Spalt, T. B., and Stead, D. J., "Acoustic Data Processing and Transient Signal Analysis for the Hybrid Wing Body 14- by 22-Foot Subsonic Wind Tunnel Test," $20^{\text {th }}$ AIAA/CEAS Aeroacoustics Conference, Atlanta, GA, June, 2014.

${ }^{10}$ Brooks, T. F., and Humphreys, W. M., Jr., "A Deconvolution Approach for the Mapping of Acoustic Sources (DAMAS) Determined from Phased Microphone Arrays," Journal of Sound and Vibration, Volume 294, pp. 856879, 2006.

${ }^{11}$ Brooks, T. F., and Humphreys, W. M., Jr., “Extension of DAMAS Phased Array Processing for Spatial Coherence Determination (DAMAS-C)," AIAA Paper 2006-2654, 12 ${ }^{\text {th }}$ AIAA/CEAS Aeroacoustics Conference, Cambridge, MA, May, 2006.

${ }^{12}$ Haubrich, R. A., “Array Design,” Bulletin of the Seismological Society of America, Volume 58, pp. $977-$ 991, 1968.

${ }^{13}$ Underbrink, J. R., “Aeroacoustic Phased Array Testing in Low-Speed Wind Tunnels," Aeroacoustic Measurements, edited by T. J. Mueller, Springer-Verlag, Berlin, pp. 98-217, 2002.

${ }^{14}$ Humphreys, W. M., Brooks, T. F., Hunter, W. W., Meadows, K. R., "Design and Use of Microphone Directional Arrays for Aeroacoustic Measurements," AIAA Paper 1998-0471, $36^{\text {th }}$ Aerospace Sciences Meeting and Exhibit, Reno, NV, January, 1998.

${ }^{15}$ Hutcheson, F. V., Brooks, T. F., Burley, C. L., Bahr, C. J., Stead, D. J., and Pope, D. S., "Shielding of Turbomachinery Noise from a Hybrid Wing Body Aircraft Configuration," $20^{\text {th }}$ AIAA/CEAS Aeroacoustics Conference, Atlanta, GA, June, 2014.

18 of 24

American Institute of Aeronautics and Astronautics 
${ }^{16}$ Doty, M. J., Brooks, T. F., Burley, C. L., Bahr, C. J., and Pope, D. S., "Jet Noise Shielding Provided by a Hybrid Wing Body Aircraft," 20 $0^{\text {th }}$ AIAA/CEAS Aeroacoustics Conference, Atlanta, GA, June, 2014.

${ }^{17}$ Burley, C. L., Brooks, T. F., Hutcheson, F. V., Doty, M. J., Lopes, L. V., and Pope, D. S., "Noise Scaling and Community Noise Metrics for the Hybrid Wing Body Aircraft," $20^{\text {th }}$ AIAA/CEAS Aeroacoustics Conference, Atlanta, GA, June, 2014.

${ }^{18}$ Brooks, T. F., Humphreys, W. M., Jr., and Plassman, G. E., "DAMAS Processing for a Phased Array Study in the NASA Langley Jet Noise Laboratory," AIAA Paper 2010-3780, 16 ${ }^{\text {th }}$ AIAA/CEAS Aeroacoustics Conference, Stockholm, Sweden, June, 2010.

${ }^{19}$ Brooks, T. F., Marcolini, M. A., and Pope, D. S., "A Directional Array Approach for the Measurement of Rotor Noise Source Distributions with Controlled Spatial Resolution," Journal of Sound and Vibration, Volume 112, Number 1, pp. 192-197, 1987.

${ }^{20}$ Marcolini, M. A., and Brooks, T. F., "Rotor Noise Measurement Using a Directional Microphone Array," Journal of the American Helicopter Society, pp. 11-22, 1992.

19 of 24

American Institute of Aeronautics and Astronautics 


\section{Appendix A - Microphone Coordinates}

The coordinates for the phased array installed in the $14 \times 22$ tunnel are listed in Table A.1. The coordinates are with respect to the center microphone in the array (i.e., in array coordinates), and are viewed from the front of the array panel.

Table A.1 - Microphone Coordinates

\begin{tabular}{|c|c|c|c|c|c|c|c|}
\hline & \multicolumn{3}{|c|}{ Coordinates (inches) } & & \multicolumn{3}{|c|}{ Coordinates (inches) } \\
\hline $\begin{array}{c}\text { Mic } \\
\text { Number }\end{array}$ & $\mathrm{X}$ & $\mathrm{Y}$ & $\mathrm{Z}$ & $\begin{array}{c}\text { Mic } \\
\text { Number }\end{array}$ & $\mathrm{X}$ & $\mathrm{Y}$ & $\mathrm{Z}$ \\
\hline 1 & 0.00 & 0.00 & 0.00 & 41 & -2.32 & -2.32 & 0.00 \\
\hline 2 & -0.76 & 0.00 & 0.00 & 42 & -4.54 & 1.88 & 0.00 \\
\hline 3 & -0.58 & 0.58 & 0.00 & 43 & -1.74 & 4.20 & 0.00 \\
\hline 4 & 0.00 & 0.76 & 0.00 & 44 & 1.88 & 4.54 & 0.00 \\
\hline 5 & 0.58 & 0.58 & 0.00 & 45 & 4.20 & 1.74 & 0.00 \\
\hline 6 & 0.76 & 0.00 & 0.00 & 46 & 4.54 & -1.88 & 0.00 \\
\hline 7 & 0.58 & -0.58 & 0.00 & 47 & 1.74 & -4.20 & 0.00 \\
\hline 8 & 0.00 & -0.76 & 0.00 & 48 & -1.88 & -4.54 & 0.00 \\
\hline 9 & -0.58 & -0.58 & 0.00 & 49 & -4.20 & -1.74 & 0.00 \\
\hline 10 & -1.14 & 0.47 & 0.00 & 50 & -6.07 & 0.00 & 0.00 \\
\hline 11 & -0.44 & 1.05 & 0.00 & 51 & -4.63 & 4.63 & 0.00 \\
\hline 12 & 0.47 & 1.14 & 0.00 & 52 & 0.00 & 6.07 & 0.00 \\
\hline 13 & 1.05 & 0.44 & 0.00 & 53 & 4.63 & 4.63 & 0.00 \\
\hline 14 & 1.14 & -0.47 & 0.00 & 54 & 6.07 & 0.00 & 0.00 \\
\hline 15 & 0.44 & -1.05 & 0.00 & 55 & 4.63 & -4.63 & 0.00 \\
\hline 16 & -0.47 & -1.14 & 0.00 & 56 & 0.00 & -6.07 & 0.00 \\
\hline 17 & -1.05 & -0.44 & 0.00 & 57 & -4.63 & -4.63 & 0.00 \\
\hline 18 & -1.52 & 0.00 & 0.00 & 58 & -9.08 & 3.76 & 0.00 \\
\hline 19 & -1.16 & 1.16 & 0.00 & 59 & -3.48 & 8.40 & 0.00 \\
\hline 20 & 0.00 & 1.52 & 0.00 & 60 & 3.76 & 9.08 & 0.00 \\
\hline 21 & 1.16 & 1.16 & 0.00 & 61 & 8.40 & 3.48 & 0.00 \\
\hline 22 & 1.52 & 0.00 & 0.00 & 62 & 9.08 & -3.76 & 0.00 \\
\hline 23 & 1.16 & -1.16 & 0.00 & 63 & 3.48 & -8.40 & 0.00 \\
\hline 24 & 0.00 & -1.52 & 0.00 & 64 & -3.76 & -9.08 & 0.00 \\
\hline 25 & -1.16 & -1.16 & 0.00 & 65 & -8.40 & -3.48 & 0.00 \\
\hline 26 & -2.27 & 0.94 & 0.00 & 66 & -12.13 & 0.00 & 0.00 \\
\hline 27 & -0.87 & 2.10 & 0.00 & 67 & -9.26 & 9.26 & 0.00 \\
\hline 28 & 0.94 & 2.27 & 0.00 & 68 & 0.00 & 12.13 & 0.00 \\
\hline 29 & 2.10 & 0.87 & 0.00 & 69 & 9.26 & 9.26 & 0.00 \\
\hline 30 & 2.27 & -0.94 & 0.00 & 70 & 12.13 & 0.00 & 0.00 \\
\hline 31 & 0.87 & -2.10 & 0.00 & 71 & 9.26 & -9.26 & 0.00 \\
\hline 32 & -0.94 & -2.27 & 0.00 & 72 & 0.00 & -12.13 & 0.00 \\
\hline 33 & -2.10 & -0.87 & 0.00 & 73 & -9.26 & -9.26 & 0.00 \\
\hline 34 & -3.03 & 0.00 & 0.00 & 74 & -18.16 & 7.522 & 0.00 \\
\hline 35 & -2.32 & 2.32 & 0.00 & 75 & -6.96 & 16.81 & 0.00 \\
\hline 36 & 0.00 & 3.03 & 0.00 & 76 & 7.52 & 18.16 & 0.00 \\
\hline 37 & 2.32 & 2.32 & 0.00 & 77 & 16.81 & 6.96 & 0.00 \\
\hline 38 & 3.03 & 0.00 & 0.00 & 78 & 18.16 & -7.52 & 0.00 \\
\hline 39 & 2.32 & -2.32 & 0.00 & 79 & 6.96 & -16.81 & 0.00 \\
\hline 40 & 0.00 & -3.03 & 0.00 & 80 & -7.52 & -18.16 & 0.00 \\
\hline
\end{tabular}

20 of 24

American Institute of Aeronautics and Astronautics 
Table A.1 - Microphone Coordinates (continued)

\begin{tabular}{|c|c|c|c|c|c|c|c|}
\hline & \multicolumn{3}{|c|}{ Coordinates (inches) } & & \multicolumn{3}{|c|}{ Coordinates (inches) } \\
\hline $\begin{array}{c}\text { Mic } \\
\text { Number }\end{array}$ & $X$ & $\mathrm{Y}$ & Z & $\begin{array}{c}\text { Mic } \\
\text { Number }\end{array}$ & $\mathrm{X}$ & $\mathrm{Y}$ & Z \\
\hline 81 & -16.81 & -6.96 & 0.00 & 91 & -13.92 & 33.61 & 0.00 \\
\hline 82 & -24.26 & 0.00 & 0.00 & 92 & 15.04 & 36.32 & 0.00 \\
\hline 83 & -18.53 & 18.53 & 0.00 & 93 & 33.61 & 13.92 & 0.00 \\
\hline 84 & 0.00 & 24.26 & 0.00 & 94 & 36.32 & -15.04 & 0.00 \\
\hline 85 & 18.53 & 18.53 & 0.00 & 95 & 13.92 & -33.61 & 0.00 \\
\hline 86 & 24.26 & 0.00 & 0.00 & 96 & -15.04 & -36.32 & 0.00 \\
\hline 87 & 18.53 & -18.53 & 0.00 & 97 & -33.61 & -13.92 & 0.00 \\
\hline 88 & 0.00 & -24.26 & 0.00 & & & & \\
\hline 89 & -18.53 & -18.53 & 0.00 & & & & \\
\hline 90 & -36.32 & 15.04 & 0.00 & & & & \\
\hline
\end{tabular}

The coordinates for the sideline tower and overhead traverse truss microphones installed in the $14 \times 22$ tunnel for the HWB test campaign are listed in Table A.2. These coordinates are with respect to the tunnel coordinate system as described in Section II. Figure A.1 depicts the numbering convention and relative location of the various microphones around the test section. Note that the $\mathrm{x}$ coordinates given in Table A.2 are relative, and the final coordinates for the tower and truss microphones are obtained by adding the traverse streamwise location in the tunnel to the $\mathrm{x}$ locations shown in the table.

Table A.2 - Tower / Truss Microphone Coordinates for HWB Test Campaign

\begin{tabular}{|c|c|c|c|c|c|c|c|}
\hline & \multicolumn{3}{|c|}{ Coordinates (inches) } & & \multicolumn{3}{|c|}{ Coordinates (inches) } \\
\hline Mic & $\mathrm{X}$ & $\mathrm{Y}$ & $\mathrm{Z}$ & Mic & $\mathrm{X}$ & $\mathrm{Y}$ & $\mathrm{Z}$ \\
\hline N0 1 & -0.13 & -192.08 & 36.48 & S0 1 & 0.29 & 230.40 & 36.97 \\
\hline N02 & -0.61 & -206.67 & 60.13 & S02 & -0.04 & 241.70 & 55.42 \\
\hline N03 & 0.09 & -212.17 & 87.14 & S03 & -0.02 & 247.89 & 87.30 \\
\hline N04 & 0.15 & -212.02 & 114.98 & S04 & -0.06 & 247.79 & 120.13 \\
\hline N05 & 0.20 & -211.98 & 143.87 & S05 & 0.14 & 247.67 & 153.72 \\
\hline N06 & 0.19 & -211.97 & 174.74 & S06 & 0.04 & 247.56 & 190.88 \\
\hline N07 & 0.03 & -211.93 & 209.16 & S07 & -0.20 & 247.47 & 230.66 \\
\hline N08 & 0.08 & -211.81 & 249.36 & S08 & -0.25 & 247.42 & 278.32 \\
\hline T01 & 5.12 & -145.70 & 246.10 & & & & \\
\hline T02 & 5.17 & -111.21 & 246.42 & & & & \\
\hline T03 & 5.042 & -91.75 & 246.43 & & & & \\
\hline T04 & 5.03 & -65.73 & 246.58 & & & & \\
\hline T05 & 5.00 & -42.44 & 246.62 & & & & \\
\hline T06 & 5.00 & -20.74 & 246.67 & & & & \\
\hline T07 & 4.98 & 0.14 & 246.65 & & & & \\
\hline T08 & 4.87 & 21.17 & 246.55 & & & & \\
\hline T09 & 4.92 & 42.77 & 246.39 & & & & \\
\hline $\mathrm{T} 10$ & 7.91 & 65.95 & 246.28 & & & & \\
\hline T11 & 8.20 & 95.09 & 246.19 & & & & \\
\hline T12 & 7.89 & 111.14 & 246.25 & & & & \\
\hline $\mathrm{T} 13$ & 4.86 & 146.39 & 246.58 & & & & \\
\hline
\end{tabular}

21 of 24

American Institute of Aeronautics and Astronautics 


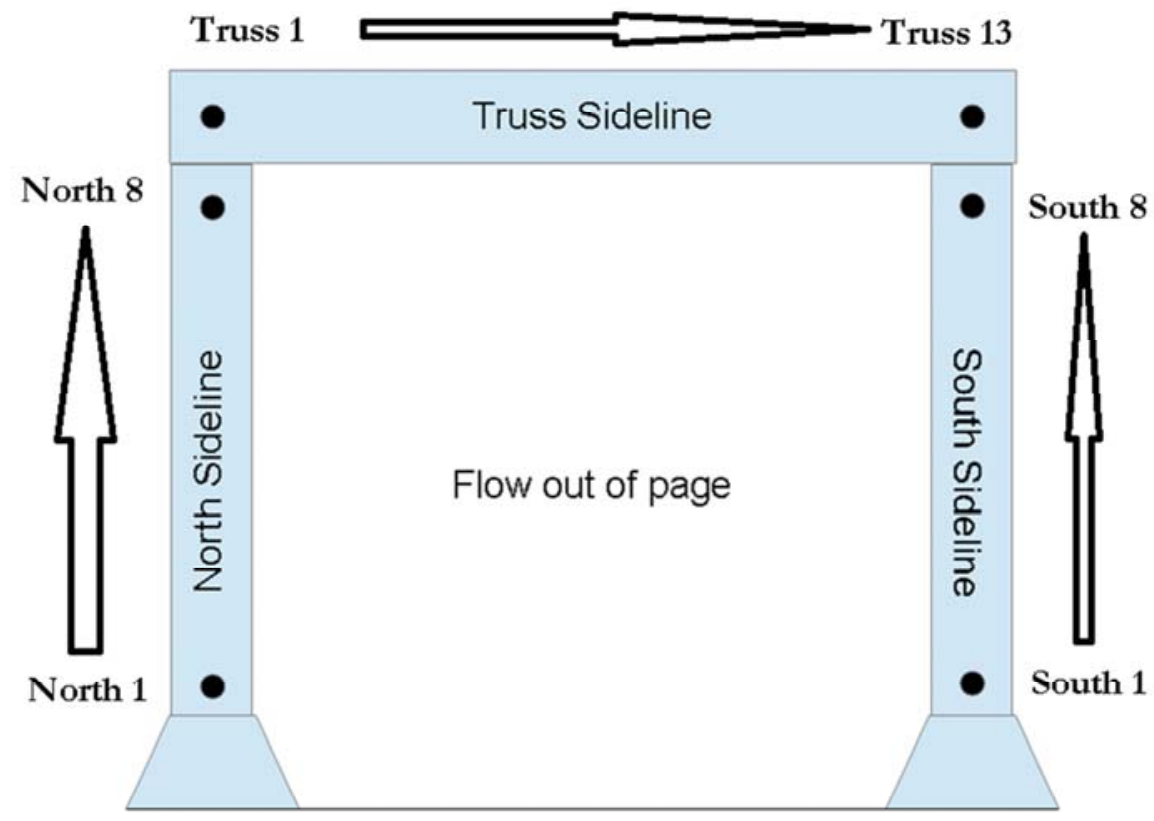

Figure A.1 - HWB Test Campaign Tower / Truss Directivity Microphone Designations and Relative Locations. Compare with Figures 3 and 6. 


\section{Appendix B - Array Shading Algorithm}

The array shading algorithm utilized in the $14 \times 22$ tunnel is a merger of previous techniques used in the Langley Quiet Flow Facility ${ }^{14}$ and Jet Noise Laboratory. ${ }^{18}$ The algorithm is composed of two parts, namely a frequency-dependent "cluster blending" technique and a frequency-independent "ring weighting" technique. A cluster blending microphone weight is denoted by " where $n$ is the

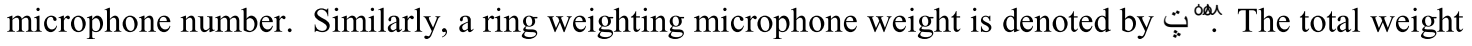
applied to a microphone is the product of the two, ๑ ๑ :

Cluster Blending: The cluster blending technique described herein is a variation of one originally developed for rotor noise measurements by Brooks and Marcolini. ${ }^{19-20}$ It is designed to produce a constant beamform resolution over a defined range of frequencies by shading inner microphone groups at low frequencies and outer groups at high frequencies. This is achieved by assigning array microphones to the five clusters shown in Table B.1.

Table B.1 - Cluster Assignments

\begin{tabular}{|c|c|c|}
\hline Cluster Number $(\mathrm{m})$ & Microphone Range (n) & Cluster Diameter $($ ), inches \\
\hline 1 & $1-33$ & 4.914 \\
\hline 2 & $34-49$ & 9.828 \\
\hline 3 & $50-65$ & 19.656 \\
\hline 4 & $66-81$ & 39.312 \\
\hline 5 & $82-97$ & 78.624 \\
\hline
\end{tabular}

The diameters 9 shown in Table B.1 are measured from the outermost pair of microphones in the $m^{\text {th }}$ cluster Each cluster exhibits beamwidth characteristics depending on the wavenumber-diameter product - , where $\mathrm{k}$ is the wavenumber. The shading method consists of weighting the array clusters as a function of frequency while retaining an adequate number of microphones in the analysis. Cluster weights are computed based on a desired $\tilde{i}$. 9 T , an effective value of the wavenumber-diameter product to be held constant over a defined frequency range. $\bar{R}$. $T$ is compared to, 9 for each 9 for a particular frequency. The shading coefficients from this comparison are defined by

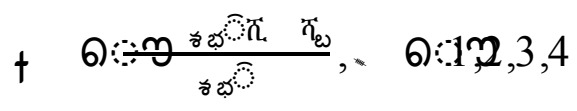

with the 9 values defined by

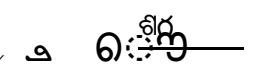

For frequencies below the lower range of the blending, the individual weights for the array microphones in each cluster are defined as

$$
\begin{aligned}
& \text { " ब1ग } \\
& \text { " का } \\
& \because \text { ब बंग } \\
& \text { म बां }
\end{aligned}
$$

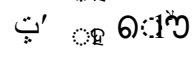

23 of 24

American Institute of Aeronautics and Astronautics 
For frequencies within the blending range, the individual weights are defined as

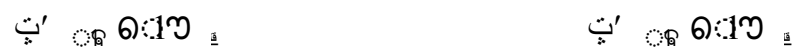

$$
\begin{aligned}
& \text { ॠ बर }
\end{aligned}
$$

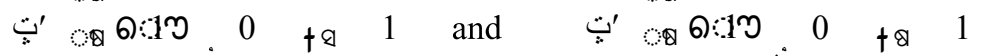

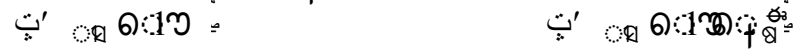

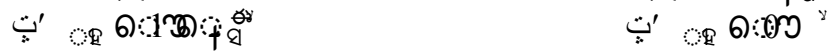

$$
\begin{aligned}
& \because \text { ब ब10 } \\
& \because \text { बार }
\end{aligned}
$$

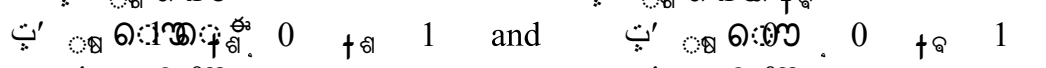

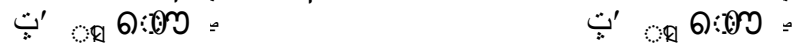

$$
\begin{aligned}
& \because \text { ब बी म }
\end{aligned}
$$

For frequencies above the upper range of the blending, the individual weights are defined as

$$
\begin{aligned}
& \because \text { का } \\
& \text { का ब० }
\end{aligned}
$$

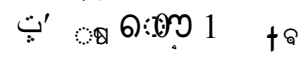

$$
\begin{aligned}
& \text { " की } \\
& \because \text { आ }
\end{aligned}
$$

Note that the subscript numbers in Eqns. (B3) through (B8) refer to cluster numbers and not microphone numbers. The microphone weights $\because$ O only if microphone $n$ is contained within cluster $m$.

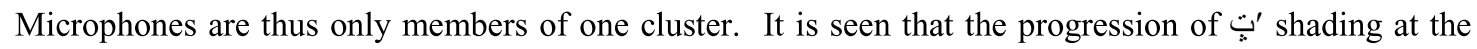
higher frequencies is stopped at cluster $m=1$ (microphones 1-33) in order to maintain enough active microphones in the array to keep sidelobe levels in check. Finally, the exponent $\alpha$ is determined empirically such that the beamform width $B$ (the diameter of the $3 \mathrm{~dB}$ down contour of the main lobe in the point spread function) is rendered nearly invariant as a function of frequency. For the examples shown in this paper, the value of $\alpha$ was set to 0.55 with the $\tilde{R} .97$ value set to 157.5.

Ring Weighting: The ring weighting algorithm chosen for use in the $14 \times 22$ tunnel is a simple linear function that does not depend on frequency:

$$
\because \text { औrom }
$$

where $د$ is the radius of microphone $n$ with respect to the center of the array and $r_{n \max }$ is 39.312 inches for the present array design. Note that the microphones can be partitioned into 24 sub-rings of 4 microphones each, with each sub-ring exhibiting a constant radius $r_{n}$. Finally, the value of $\because$ was set to 0.0 for the examples shown in this paper, implying from Eqn. (B9) that the central microphone in the array is always given unity weighting.

24 of 24

American Institute of Aeronautics and Astronautics 